\title{
PCCP
}

\section{Mechanical Properties of Anhydrous Oxalic Acid and Oxalic Acid Dihydrate}

Received 00th January 20xx, Accepted 00th January 20xx

DOI: $10.1039 / x 0 x \times 00000 x$

www.rsc.org/

\author{
Francisco Colmenero*a
}

The mechanical properties of oxalic acid dihydrate and anhydrous oxalic acid ( $\alpha$ and $\beta$ polymorphic forms) were obtained by using rigorous theoretical solid-state methods based in Density Functional Theory using plane waves and pseudopotentials. The calculated crystal structures and X-ray powder diffraction patterns of these materials were found to be in excellent agreement with the experimental information. Since the calculated elasticity matrices fullfilled the Born stability conditions, the corresponding crystal structures were found to be mechanically stable. A large amount of relevant mechanical properties including the values of the bulk modulus and their pressure derivatives, shear and Young moduli, Poisson ratio, ductility and hardness indices, as well as mechanical anisotropy measures of these materials were reported. The three forms of the oxalic acid are highly anisotropic ductile materials having low hardness and bulk moduli. The three materials are shown to display small negative Poisson ratios (NPR) and to exhibit the phenomenon of negative linear compressibility (NLC) for applied pressures along the direction of minimum Poisson ratio. In addition, they undergo pressure induced phase transitions for relatively small applied pressures. The analysis of the crystal structures of these materials as a function of pressure demonstrates that the mechanism of NLC of these materials is unrelated to the wine-rack structural mechanism commonly used to rationalize this phenomenon. The three forms of oxalic acid considered in this work are molecular crystals whose structures are characterized by structural elements which are not directly bonded but held together by weak van der Waals forces. The weak bonding between these elements is able to accommodate the structural variations originated by the application of pressure, but the resulting structural deformations appear to be counterintuitive and lead to the anomalous mechanical behavior of these materials.

\section{Introduction}

Oxalic, or ethanedioic acid, is an organic toxic compound with the formula $\mathrm{C}_{2} \mathrm{H}_{2} \mathrm{O}_{4} \cdot{ }^{1}$ It is a colorless crystalline solid that forms a colorless solution in water. Its condensed formula, $\mathrm{HOOCCOOH}$, reflects its classification as the simplest dicarboxylic acid. The preparation of salts of oxalic acid from plants is known from 1745 when Boerhaave ${ }^{2}$ isolated a salt from sorrel. In 1773, Savary ${ }^{3-4}$ isolated oxalic acid from this salt in sorrel. Oxalic acid was first prepared synthetically in 1776 by Scheele and Bergman. ${ }^{5-6}$ In 1824, Wöhler ${ }^{7}$ obtained oxalic acid by reacting cyanogen with ammonia in aqueous solution. This experiment represents the first synthesis of a natural product. ${ }^{8}$ It is manufactured ${ }^{8}$ by heating sodium formate in the presence of an alkali catalyst, by oxidizing carbohydrates with nitric acid ${ }^{9}$, by heating sawdust with caustic alkalis, or by fermentation of sugar solutions in the presence of certain molds. Solid oxalic acid dihydrate can be dehydrated with heat or azeotropic distillation. ${ }^{10-11}$ An electrochemical process has been proposed to reduce carbon dioxide to oxalic acid. ${ }^{12}$ This process is

\footnotetext{
a. Instituto de Estructura de la Materia - Consejo Superior de Investigaciones Científicas (IEM-CSIC). C/ Serrano, 123 - 28006 Madrid - Spain. E-mail: francisco.colmenero@iem.cfmac.csic.es. Orcid number: https://orcid.org/00000003-3418-0735;

Electronic Supplementary Information (ESI) available: Atom numbering convention employed for oxalic acid dihydrate, $\alpha$-oxalic acid, and $\beta$-oxalic acid crystal structures.
} See DOI: $10.1039 / x 0 x x 00000 x$ interesting to reduce global warming since uses carbon dioxide as a feedstock to generate oxalic acid. The name of this acid was coined by the early investigators which isolated this compound from wood-sorrel family (Oxalis) flowering plants. ${ }^{2-4}$

Oxalic acid is an extremely important material which has found an enormous range of applications in science, medicine and industry. For this reason, its physico-chemical properties have been studied in great detail. ${ }^{13-50}$ However, in view of the great importance of the study of the mechanical behavior of solid materials, it was surprising to found that its mechanical properties have not been studied in deep, despite of the existence of several published works related directly with this issue. ${ }^{13-23}$ Most of these important studies ${ }^{13-21}$ are related to the behavior of the hydrogen bond structure and electron density of oxalic acid under pressure, because this and related compounds have been taken among the more important models to study the characteristics of the hydrogen bonding and the obtention and representation of the electron density function of crystalline solids from X-ray diffraction data. ${ }^{24-40}$ The representation of oxalic acid dihydrate electron density by reconstruction of an $\mathrm{N}$-electron wavefunction has been achieved. ${ }^{39}$ As it will be shown in this paper, the mechanical behavior of oxalic acid is highly anomalous since it exhibits the important negative Poisson ratio (NPR) $)^{51-53}$ and negative linear compressibility (NLC) ${ }^{54-56}$ phenomena. The exhibition of these important phenomena in oxalic acid has not been noted in the 
previously published works. ${ }^{13-23}$ The materials displaying these phenomena have found a large number of useful applications resulting specifically form their mechanical behaviour. ${ }^{51-56}$ Besides, anhydrous oxalic acid and oxalic acid dihydrate are shown to undergo pressure induced phase transitions for relatively small external pressures. The presence of these pressure induced phase transitions is relevant in the highpressure research of crystals of organic compounds which is a well-established field. ${ }^{57-59}$ As shown in previous works, other simple organic materials also display anomalous mechanical properties. ${ }^{60-61}$ Therefore, the study of the mechanical behavior of organic compounds, which has rarely been investigated, may open a new range of interesting applications for these compounds. Our previous studies prescribe that for highly anisotropic organic materials, as oxalic acid, their mechanical behavior along the direction of minimum Poisson ratio should be studied in the search for anomalous negative mechanical properties. ${ }^{60-62}$ The existence of a symmetry independent correlation between the value of the elastic anisotropy ${ }^{63}$ and the values of the maximum and minimum Poisson ratios of a given material, taking into account all possible longitudinal and transverse directions is known. ${ }^{64-65}$ However, the existence of negative linear compressibilities has also been found accompanying negative Poisson ratios along the minimum NPR direction. ${ }^{60-61}$

The usual form of oxalic acid in the solid state is that of the crystalline dihydrate, $(\mathrm{COOH})_{2} \cdot 2 \mathrm{H}_{2} \mathrm{O} \cdot{ }^{24-36}$ For anhydrous oxalic acid exists two polymorphic forms. ${ }^{37}$ The $\alpha$-polymorph has a chain-like structure whereas the $\beta$ form has sheet-like structure ${ }^{66.37}$ While for the dihydrate two polymorphic forms are also known, $\alpha$ and $\beta,{ }^{29,14,35,42,67-70}$ which differ mainly in their hydrogen bonding arrangements, the first is by far the most widely used in actual applications and has been studied here. Therefore, unless noted explicitly, the polymorphic form of oxalic acid dihydrate studied in this paper is the $\alpha$ one. Oxalic acid is a relatively strong acid, despite being a carboxylic acid Oxalic acid has a large number of applications in the laboratory as an analytical reagent and as a general reducing agent. ${ }^{8}$ The concentration of oxalic acid in solution may be determined with precision by titration with potassium permanganate. ${ }^{71}$ Oxalate, the conjugate base of oxalic acid, is used as an excellent chelating agent for metal cations. ${ }^{72}$ Oxalic acid is an important reagent in extractive metallurgy because hydrated lanthanide oxalates $^{73}$ are readily formed in very strongly acidic solutions and their thermal decomposition permits to recover these elements.

Oxalic acid dihydrate is a promising phase change material which may be very useful for thermal energy storage. ${ }^{74-75}$ One of the most typical applications of oxalic acid is as an actinometer used as a standard for measurement of light energies involved in photochemical works. ${ }^{76-77}$ Some esters of oxalic acid may be used in practical applications requiring organic chemiluminescent materials. ${ }^{1}$ Oxalic acid has been observed as a degradation product in the bitumen used to encapsulate radioactive waste resulting from the reprocessing of spent nuclear fuel exposed to gamma rays. The presence of oxalic acid may increase the leaching of radionuclides conditioned in bitumen for radioactive waste disposal. ${ }^{78}$ Oxalic acid under natural conditions is not toxic but becomes so because of the formation of oxalate ion. The excessive ingestion of oxalic acid or the prolonged skin contact with this compound can be dangerous. ${ }^{79-80}$ This compound is also widely used as an acid rinse in laundries, where it is effective in removing rust and ink stains because it converts most insoluble iron compounds into a soluble complex ion. For the same reason, it is the main constituent of many preparations used for removing scale from automobile radiators. Oxalic acid is also used as a bleaching agent and as a fixative dye substance.

Oxalic acid occurs widely in nature. For example, it is present in many plants and vegetables and in mineral assemblages. The members of the spinach family, the brassicas, sorrel and umbellifers such as parsley have high content of oxalates. ${ }^{81}$ Oxalic acid play an important role in human nutrition ${ }^{1}$, because it has a great influence in metal absorption and thus in the availability to the human body. It is also is produced by the body of many living organisms. Oxalic acid is produced in the Krebs citric acid cycle ${ }^{82}$ and in the metabolism of ethylene glycol and glyoxylic and ascorbic acids. ${ }^{1}$ Oxalic acid is not metabolized but excreted in the urine. Calcium oxalate is the most common component of human kidney stones. ${ }^{83-85}$ Oxalates also result from oxidation of carbohydrates in bacterial organisms. ${ }^{8}$ The conjugate bases of oxalic acid, the hydrogen oxalate and oxalate anions, $\mathrm{C}_{2} \mathrm{O}_{4} \mathrm{H}^{-}$and $\mathrm{C}_{2} \mathrm{O}_{4}{ }^{2-}$, are competitive inhibitors of the lactate dehydrogenase (LDH) enzyme ${ }^{86}$ The inhibition of LDH, inhibits tumor formation and growth, 80 and, therefore, oxalic acid and related compounds have potential uses in the cancer treatment. Oxalates are also produced during the degradation of ancient paintings, sculpture, and architectural works. ${ }^{87-94}$ The main process responsible of the formation of these oxalate compounds is the chemical reaction of carbonate stones with oxalic acid secreted by lichen or other microorganisms. ${ }^{94}$ Oxalic acid is the most common organic acid in the atmosphere and it has been recognized as significant precursor in atmospheric new particle formation. ${ }^{95-96}$ The interaction between oxalic acid and other species in the atmosphere in the presence of hydration and its relevance in the description of global atmospheric chemistry is currently under investigation. ${ }^{96}$

Because oxalic acid dihydrate and the $\alpha$ and $\beta$ polymorphic forms of anhydrous oxalic acid were found to be highly anisotropic materials in preliminary theoretical solid-state studies of these materials, their mechanical properties were reinvestigated using accurate theoretical calculations with special emphasis in the study of the associated Poisson ratios. The theoretical solid-state methods used here are based in Density Functional Theory (DFT) using plane waves and pseudopotentials. ${ }^{97}$ These methods have already been employed successfully in order to study the mechanic properties of a series of uranyl containing materials. ${ }^{98-106}$ There are many recent published works in which the first-principles theoretical methodology has been employed in the research of materials exhibiting negative Poisson ratio (NPR) and negative linear compressibility (NLC). ${ }^{107-132}$ For example, one may cite the works by Keskar and Chelikowsky ${ }^{107}$ and Grima et al. ${ }^{108}$ on crystalline $\mathrm{SiO}_{2}$, Grima et al. ${ }^{109}$ and Coudert et al. ${ }^{110-111}$ on 
several zeolitic compounds, Yao et al. ${ }^{112}$ on crystalline cellulose, Tan et al. ${ }^{113-114}$ on zeolitic imidazolate frameworks (ZIFs), Sun et al. ${ }^{115}$ on penta-graphene and phagraphene, Du et al. ${ }^{116}$ on black phosphorus, Li et al.117 on an ammonium-zinc metal-organic framework, Qiao et al. ${ }^{118}$ on oxammite mineral, Coates et al. ${ }^{119}$ on $\mathrm{Cd}\left(\mathrm{NH}_{3}\right)_{2}\left[\mathrm{Cd}(\mathrm{CN})_{4}\right]$, Marmier et al. ${ }^{120}$ on cooperite mineral, and Kang et al. ${ }^{121}$ on $\alpha-\mathrm{BiB}_{3} \mathrm{O}_{6}$. The description of solid-state crystalline compounds using computational modelling techniques, appears to be sufficiently advanced nowadays to predict their mechanical properties in good agreement with experimental values.

The main objective of this paper is to unveil the anomalous mechanical behavior of oxalic acid. This paper is organized as follows. The computational methodology used in this work is described in Section 2. Then, in Section 3, the main results of this work are given and discussed. This section contains three main Subsections, 3.1, 3.2 and 3.3. In the first one the structural properties of the considered materials are studied and, in the second one, the corresponding $\mathrm{X}$-ray diffraction patterns are reported. In the last subsection, the mechanical properties of these materials and the mechanical stability of the corresponding crystal structures are studied. In this same subsection the anomalous mechanical behavior of these materials is described. Finally, the conclusions of this work are presented in Section 4.

\section{Computational solid-state methods}

The generalized gradient approximation (GGA) together with Perdew-Burke-Ernzerhof functional ${ }^{133}$ supplemented with Grimme empirical dispersion correction, ${ }^{134}$ was used to study the crystal structures and mechanical properties of the oxalic acid dihydrate and the $\alpha$ and $\beta$ polymorphs of anhydrous oxalic acid. The addition of dispersion corrections improved the computed structural and mechanical properties in a significant way as a consequence of the better description of the hydrogen bonding present in their unit cell structures. This approach, referred to as DFT-D2, is implemented in the CASTEP program, ${ }^{135}$ a module of the Materials Studio package, ${ }^{136}$ which was employed to model the structures of the materials considered. The pseudopotentials employed for the hydrogen, carbon and oxygen ions in the structures of these materials were standard norm-conserving pseudopotentials ${ }^{137}$ provided by CASTEP.

The atomic positions and cell parameters were optimized by using the Broyden-Fletcher-Goldfarb-Shanno method ${ }^{138}$ with a convergence threshold on atomic forces of $0.01 \mathrm{eV} / \AA . \AA$. This method was also used in order to optimize the structures of the materials considered under the effect of different applied pressures. The structures of the materials considered in this work were optimized in calculations with augmented complexity by increasing the calculation parameters. These parameters, the kinetic energy cut-off $(\varepsilon)$ and k-point mesh, 139 were chosen to ensure good convergence for computed structures and energies. The structures were only accepted as satisfactory if the computed X-ray powder diffraction pattern obtained from the computed crystal structure ${ }^{140}$ was in agreement with the experimental pattern. ${ }^{141}$ The precise calculation parameters used to determine the final results may be found in Table 1.

The elastic constants required to calculate the mechanical properties of the considered materials and to study the mechanical stability of their crystal structures were obtained from stress-strain relationships using the finite deformation method. ${ }^{142}$ In this technique, the individual elastic constants are determined from the stress tensor resulting from the response of the material to finite programmed symmetry-adapted strains. ${ }^{143}$ The energy-based methods and the use of Density Functional Perturbation Theory ${ }^{144}$ appear to be less efficient than this stress-based method for the calculation of the elasticity tensor. ${ }^{142}$ The derivatives of the bulk modulus with respect to pressure were determined by performing fits of the unit cell volumes and associated pressures to a fourth-order Birch-Murnahan $^{145}$ equation of state (EOS). The unit cell volumes in the vicinity of the optimized structure were calculated by optimizing the geometry of the material considered under seventeen different applied isotropic pressures within -1.0 to $12.0 \mathrm{GPa}$. The fits of the pressurevolume data to the chosen EOS were carried out using EOSFIT 5.2 computer program. ${ }^{146}$

\section{Results and discussion}

\subsection{Crystal structures}

\subsubsection{Oxalic acid dihydrate}

\subsection{1.a. Calculated crystal structure}

Table 1 gives the final calculation parameters used in order to optimize the monoclinic crystal structure of oxalic acid dihydrate. The calculated lattice parameters, volume, and density are given in Table 2, where they are compared with the experimental values given by various authors at several temperatures. ${ }^{26-27,32}$ The data from Wang et al. ${ }^{32}$ shows that the agreement with the experimental information is very good. The differences in the calculated cell volume and density compared with the experimental values at $300 \mathrm{~K}$ are large, about $6.3 \%$. The reason for the large differences is the dependence of the structural parameters with respect to temperature. The results from the theoretical calculations refer to the temperature of 0 $\mathrm{K}, 147,60$ and the differences with respect to the experiment data improve significantly for the temperatures of 225, 170, 130, and $100 \mathrm{~K}$, the differences being 4.6, 3.5, 3.2, and $2.7 \%$, respectively. ${ }^{32}$

The computed crystal structure of the oxalic acid dihydrate is shown in Fig. 1, where views of the unit cell from [100], [001], and [001] directions are provided. A larger scale view of the structure is shown in Fig. 2.A, where a $2 \times 2 \times 2$ supercell is displayed. The last figure allows to appreciate adequately the chain structure of this material. As can be seen, the structure of this material is composed of hydrogen bonded oxalic acid and water isolated molecules. While the oxalic acid molecules are not bonded directly, but linked through intervening water molecules, they are placed in parallel planes which interact by means of weak van der Waals forces. 
Table 1. Material data and calculation parameters.

\begin{tabular}{cccccc}
\hline Material & Structural formula & Crystal system & Space group & $\boldsymbol{\varepsilon}(\mathrm{eV})$ & k-mesh \\
\hline Oxalic acid dihydrate & $\mathrm{C}_{2} \mathrm{O}_{4} \mathrm{H}_{2} \cdot 2 \mathrm{H}_{2} \mathrm{O}$ & Monoclinic & $P 12_{1} / \mathrm{c} 1$ (no. 14) & 1000 & $2 \times 4 \times 1$ \\
$\boldsymbol{\alpha}$-Oxalic acid & $\alpha-\mathrm{C}_{2} \mathrm{O}_{4} \mathrm{H}_{2}$ & Orthorhombic & $P$ bca (no. 61) & 950 & $3 \times 3 \times 3$ \\
$\boldsymbol{\beta}$-Oxalic acid & $\beta-\mathrm{C}_{2} \mathrm{O}_{4} \mathrm{H}_{2}$ & Monoclinic & $P 12_{1} /$ c1 (no. 14) & 950 & $5 \times 4 \times 5$ \\
\hline
\end{tabular}

Table 2. Lattice parameters of the oxalic acid dihydrate and the $\alpha$ and $\beta$ polymorphic forms of anhydrous oxalic acid.

\begin{tabular}{|c|c|c|c|c|c|c|c|c|}
\hline Parameter & $a(\AA ̊)$ & $b(\AA ̊)$ & $c(\AA ̊)$ & $\alpha$ & $\boldsymbol{\beta}$ & $\gamma$ & Vol. $\left(\AA^{3}\right)$ & Dens. $\left(\mathrm{g} / \mathrm{cm}^{3}\right)$ \\
\hline \multicolumn{9}{|c|}{ Oxalic acid dihydrate } \\
\hline DFT & 6.0322 & 3.5360 & 11.5718 & 90.0 & 104.14 & 90.0 & 239.3515 & 1.750 \\
\hline Exp. $^{26-27}-298 \mathrm{~K}$ & 6.119 & 3.607 & 12.057 & 90.0 & 106.19 & 90.0 & 255.56 & 1.639 \\
\hline Exp. $^{32}-300 K$ & 6.120 & 3.6058 & 12.057 & 90.0 & 106.29 & 90.0 & 255.39 & 1.640 \\
\hline Exp. $^{32}-225 \mathrm{~K}$ & 6.109 & 3.5595 & 12.008 & 90.0 & 106.02 & 90.0 & 250.97 & 1.669 \\
\hline Exp. $^{32}-170 \mathrm{~K}$ & 6.102 & 3.5298 & 11.978 & 90.0 & 105.89 & 90.0 & 248.13 & 1.688 \\
\hline Exp. $^{32}-130 \mathrm{~K}$ & 6.102 & 3.5190 & 11.973 & 90.0 & 105.84 & 90.0 & 247.33 & 1.694 \\
\hline Exp. $^{32}-100 \mathrm{~K}$ & 6.102 & 3.5011 & 11.964 & 90.0 & 105.79 & 90.0 & 245.95 & 1.703 \\
\hline \multicolumn{9}{|c|}{$\alpha$-Oxalic acid } \\
\hline DFT & 6.6263 & 7.6105 & 6.1397 & 90.0 & 90.0 & 90.0 & 309.6211 & 1.931 \\
\hline Exp..$^{37}$ & 6.548 & 7.844 & 6.086 & 90.0 & 90.0 & 90.0 & 312.592 & 1.913 \\
\hline \multicolumn{9}{|c|}{$\beta$-Oxalic acid } \\
\hline DFT & 5.2743 & 5.9936 & 5.3998 & 90.0 & 114.755 & 90.0 & 155.0130 & 1.929 \\
\hline Exp. ${ }^{37}$ & 5.330 & 6.015 & 5.436 & 90.0 & 115.83 & 90.0 & 156.866 & 1.906 \\
\hline
\end{tabular}

A.1. [100]

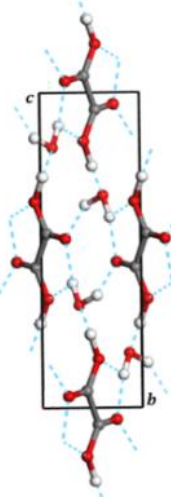

B.1. [010]

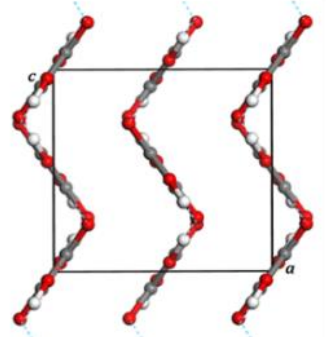

C.1. [100]

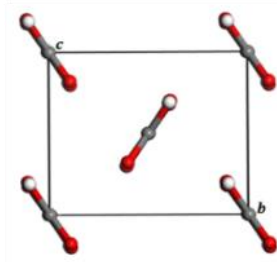

A.2. $[010]$

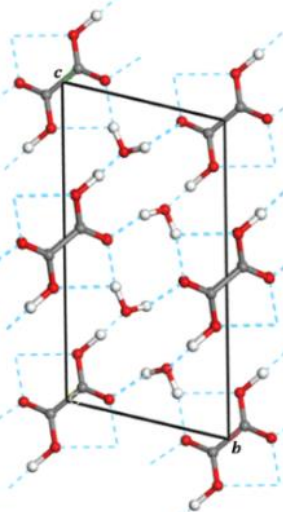

B.2. [100]

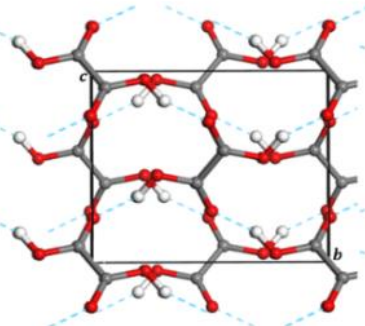

C.2. $[010]$

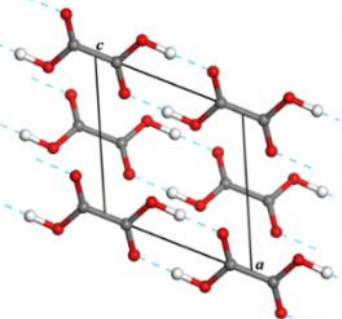

A.3. [001]

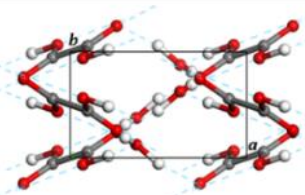

B.3. [001]

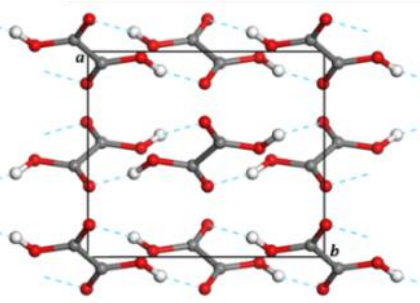

C.3. [001]

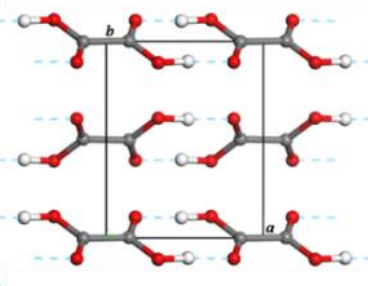

Figure 1. Calculated crystal structures of (A) oxalic acid dihydrate, (B) $\alpha$-oxalic acid and (C) $\beta$-oxalic acid. For each material, the corresponding views of the unit cell from [100], [010] and [001] directions are given. Color code: Grey-C; Red-O; White-H. 
A

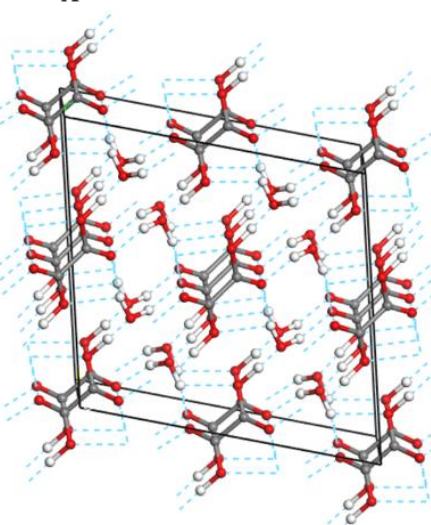

B

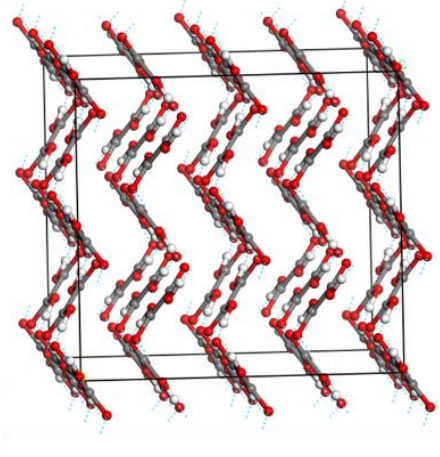

C

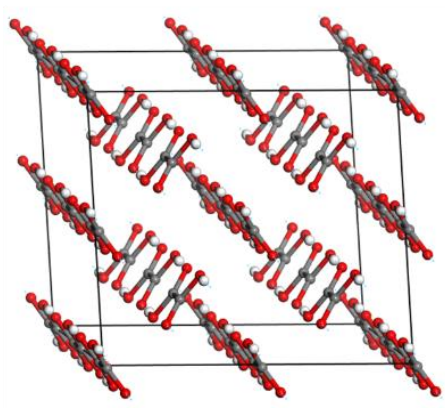

Figure 2. Views of $2 \times 2 \times 2$ supercells of (A) oxalic acid dihydrate, (B) $\alpha$-oxalic acid, and (C) $\beta$-oxalic acid. Color code is the same as in Fig.1.

\subsection{1.b. Bond lengths and angles}

The computed bond distances and bond angles are shown in Table S1 and Table S2 of the Supplementary Information, respectively, where they are compared with the corresponding experimental values from Sabine et al. ${ }^{26}$ and Delaplane et al. ${ }^{27}$ The atom numbering convention employed is shown in Fig. S1 of the Supplementary Information. Note that in the notation employed in the tables for the bond distances and angles, the super-index \# is used to differentiate two distinct atoms of the same kind belonging to the same molecule in the crystal. As can be seen, the calculated values are in good agreement with their experimental counterparts. The $\mathrm{C} 1-\mathrm{C}^{\#}, \mathrm{C} 1-\mathrm{O} 1$, and $\mathrm{C} 1-\mathrm{O} 2$ bond distances are $1.54,1.29$, and $1.21 \AA$ which are comparable to the calculated distances of $1.56,1.29$, and $1.24 \AA$. The carbonyl group accepts two strong hydrogen bonds $(\mathrm{O} 3-\mathrm{H} 2 \cdots \mathrm{O} 2$ and $\mathrm{O} 3-\mathrm{H} 3 \cdots \mathrm{O} 2)$, which are almost linear and have $\mathrm{R}\left(\mathrm{H}_{2} \cdots \mathrm{O} 2\right)$ and $\mathrm{R}(\mathrm{H} 3 \cdots \mathrm{O} 2)$ values close to $2.0 \AA$. The calculated values of these distances are 1.75 and $1.79 \AA$. Similarly, the oxygen atom in the $\mathrm{OH}$ group donates a nearly linear hydrogen bond $(\mathrm{O} 1-\mathrm{H} 1 \cdots \mathrm{O} 3)$ with $\mathrm{R}(\mathrm{H} 1 \cdots \mathrm{O} 3)$ of about $1.65 \AA$ comparable to the calculated value of $1.32 \AA$. The differences, as in the case of the lattice parameters, volume and density, may be due to temperature effects, 147,60 since the experimental values were obtained from neutron and X-ray diffraction data at room temperature, ${ }^{26-27}$ respectively. The large discrepancies between the $\mathrm{O}-\mathrm{H}$ and $\mathrm{H} \cdots \mathrm{O}$ distances in the $\mathrm{X}$-ray and neutron data given in Table 3 are due to the very small scattering factor of hydrogen, that makes the hydrogen locations very unprecise.

\subsection{2 $\alpha$-Oxalic acid}

\subsection{2.a. Calculated crystal structure}

The orthorhombic crystal structure of the $\alpha$-oxalic acid was optimized using the calculation parameters provided in Table 1. The calculated lattice parameters, volume, and density are given in Table 2, where they are compared with the experimental values given by Derisen and Smit. ${ }^{37}$ The experimental data were reproduced accurately. The differences in the calculated cell volume and density compared with the experimental values were about $0.9 \%$.
The computed crystal structure of $\alpha$-oxalic acid is shown in Fig. 1. In this Figure, views of the unit cell from [010], [100], and [001] directions are displayed. A larger scale view of the structure is shown in Fig. 2.B, where a $2 \times 2 \times 2$ supercell is shown. As may be appreciated, the structure of this material is composed of hydrogen bonded oxalic acid molecules forming folded zig-zag sheets. The sheets are electroneutral and are not bonded; they are held together only by weak van der Waals forces (see Fig. 2.B).

\subsection{2.b. Bond lengths and angles}

The computed bond distances and bond angles are shown in Table S3 and Table S4 of the Supplementary Information, respectively, where they are compared with the corresponding experimental values from Derisen and Smit. ${ }^{37}$ The atom numbering convention employed is shown in the Fig. S2 of the Supplementary Information. As can be seen, the computed values are in very good agreement with their experimental counterparts. The $\mathrm{C} 1-\mathrm{C} 1 \#, \mathrm{C} 1-\mathrm{O} 1$, and $\mathrm{C} 1-\mathrm{O} 2$ bond distances are $1.54,1.21$, and $1.31 \AA$, which are comparable to the calculated distances of $1.55,1.23$, and $1.31 \AA$. The carbonyl group accepts one nearly linear strong hydrogen bond $(\mathrm{O} 2-\mathrm{H} 1 \cdots \mathrm{O} 1)$ having $\mathrm{R}(\mathrm{O} 1-\mathrm{-}-\mathrm{O} 2)=2.65 \AA$, which agrees very satisfactorily with the calculated value of $2.60 \AA$.

\subsection{3 $\beta$-Oxalic acid}

\subsection{3.a. Calculated crystal structure}

The monoclinic crystal structure of the $\beta$-oxalic acid was optimized by performing increasingly complex calculations using very demanding convergence criteria. Table 1 gives the final calculation parameters used. The calculated lattice parameters, volume, and density are given in Table 2, where they are compared with the experimental values given by Derisen and Smit. ${ }^{37}$ The experimental data were reproduced accurately. The differences in the calculated cell volume and density compared with the experimental values were about $1.2 \%$.

The calculated structure of $\beta$-oxalic acid is shown in Fig. 1, where images of the unit cell from [100], [010], and [001] directions are displayed. The view of the structure given in Fig. 2.C shows a $2 \times 2 \times 2$ supercell. Clearly, the structure of the $\beta$ - 
oxalic acid crystal is formed of hydrogen bonded oxalic acid molecules forming chains. As for $\alpha$-oxalic acid, the chains are held together by weak van der Waals forces only.

\subsection{3.b. Bond lengths and angles}

The bond distances and angles determined from the optimized structure of the $\beta$-oxalic acid are given in Table S3 and Table S4 of the Supplementary Information, respectively. In these tables, the calculated geometrical parameters are compared with the experimental ones from Derisen and Smit. ${ }^{37}$ The atom numbering convention employed is shown in Fig. S3 of the Supplementary Information. As for the previous materials, the theoretical results are in good agreement with the corresponding experimental data. The carbonyl group accepts one nearly linear strong hydrogen bond $(\mathrm{O} 2-\mathrm{H} 1 \cdots \mathrm{O} 1)$ having $\mathrm{R}(\mathrm{O} 1--\mathrm{O} 2)=2.70 \AA$ which agrees very satisfactorily with the calculated value of $2.69 \AA$.

\subsection{X-ray powder diffraction patterns}

The X-ray powder diffraction patterns for the oxalic acid dihydrate and the $\alpha$ and $\beta$ polymorphic forms of anhydrous oxalic acid were derived ${ }^{140}$ from the experimental ${ }^{26,37}$ and computed structures using $\mathrm{CuK}_{\alpha}$ radiation $(\lambda=1.540598 \AA$ ) employing the REFLEX module of Materials Studio. ${ }^{136}$ As can be observed in Fig. 3, the calculated patterns are in excellent agreement with the experimental ones. For oxalic acid dihydrate the calculated X-Ray powder diffraction patterns are also compared with the experimental diffractogram reported by Fischer et al. ${ }^{148}$ (referred to as Experimental(a) in Fig.3.A) and as may be appreciated they are in excellent agreement. The good agreement gives additional support to the calculated structures and the computational treatment used for these materials. A detailed discussion of the variation of the X-ray powder diffraction patterns as a function of applied pressures will be given in Section 3.3.4.

\subsection{Mechanical properties and stability}

\subsubsection{Mechanical stability}

Materials with monoclinic and orthorhombic unit cells have 13 and 9 non-degenerate elastic constants in the symmetric stiffness $C$ matrix, ${ }^{143,105}$ respectively. The computed values of these constants for oxalic acid dihydrate and the $\alpha$ and $\beta$ polymorphic forms of anhydrous oxalic acid are given in Table 3. In this table, the standard Voigt notation for the indices of the elements of the $C$ matrix $\left(C_{i, j}\right)$ is used. ${ }^{143}$ For orthorhombic systems a set of necessary and sufficient Born conditions ${ }^{149}$ for mechanical stability are known. ${ }^{150,105}$ These conditions can be written as a set of algebraic inequalities among products of elastic constants and were adequately satisfied by the computed stiffness tensors for $\alpha$-oxalic acid. In the case of monoclinic materials, the generic necessary and sufficient Born criterion of stability is that all eigenvalues of the stiffness $C$ matrix be positive. ${ }^{150}$ The stiffness matrix of the oxalic acid dihydrate and $\alpha$-oxalic acid was diagonalized numerically and al eigenvalues were positive. Therefore, the three materials considered are mechanically stable.
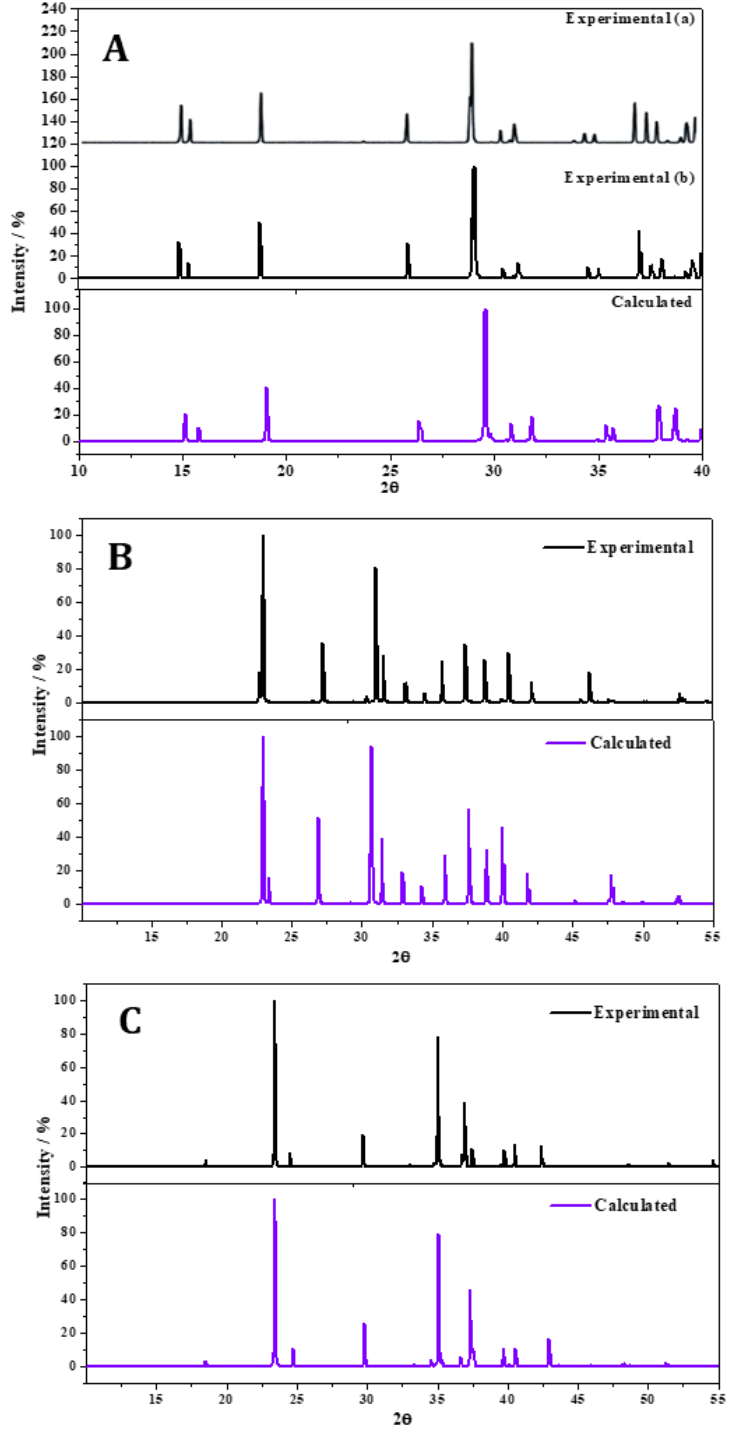

Figure 3. X-Ray powder patterns of (A) oxalic acid dihydrate, (B) $\alpha$ oxalic acid, and (C) $\beta$-oxalic acid using $\mathrm{CuK}_{\alpha}$ radiation. The X-Ray powder diffraction patterns computed from the experimental ${ }^{26,37}$ and calculated geometries are displayed for the three materials. For oxalic acid dihydrate, the experimental diffractogram from Fischer et $a .^{148}$ is also given (Experimental(a)).

\subsubsection{Mechanical properties}

The mechanical properties of polycrystalline oxalic acid dihydrate and the $\alpha$ and $\beta$ polymorphic forms of anhydrous oxalic acid were determined according to the Voigt, ${ }^{151}$ Reuss, ${ }^{152}$ and Hill ${ }^{153}$ schemes. These schemes provide very different results for systems characterized by a large anisotropy. ${ }^{105,98}$ As may be observed in Table 3 the three materials considered are very anisotropic mechanically because the corresponding elastic constants are very different in the three directions ( $i=1,2,3$, for the $x, y$, and $z$ directions). The Reuss approach was chosen as the best one in the three cases because it provided the best approximation to the bulk modulus computed from the equation of state (see Section 3.3.3). The results obtained for the bulk, shear, and Young moduli, and the Poisson ratio $(B, G$, $E$, and $v$, respectively) are given in Table 4 . Also, the ductility ${ }^{154}$ 
and hardness ${ }^{155}$ indices were determined. The three materials are ductile because the ductility index, $D$, is larger than 1.75. ${ }^{154,156}$ The computed values of the Vickers hardness, $H$, for these compounds were $0.3,1.1$, and 0.4 , respectively. These values correspond to materials of very low hardness. ${ }^{155,103-104}$

In order to assess the elastic anisotropy of these materials, shear anisotropic factors were obtained. These factors give a measure of the degree of anisotropy in the bonding between atoms in different planes and are important parameters to study the material durability. ${ }^{156-157}$ Shear anisotropic factors for the $\{100\}\left(A_{1}\right),\{010\}\left(A_{2}\right)$, and $\{001\}\left(A_{3}\right)$ crystallographic planes were computed. These factors may be written as: ${ }^{156-157}$

$$
\begin{gathered}
A_{1}=4 C_{44} /\left(C_{11}+C_{33}\right) \\
A_{2}=4 C_{55} /\left(C_{22}+C_{33}-C_{23}\right) \\
A_{2}=4 C_{66} /\left(C_{11}+C_{22}-2 C_{12}\right)
\end{gathered}
$$

For an isotropic crystal, the factors $A_{1}, A_{2}$, and $A_{3}$ must be one, while any value smaller or greater than unity is a measure of the degree of elastic anisotropy possessed by a crystal. As seen in Table 5, the $\{001\},\{100\}$, and $\{010\}$ planes are the most anisotropic for oxalic acid dihydrate and the $\alpha$ and $\beta$ polymorphic forms of anhydrous oxalic acid, respectively ( $A_{3}, A_{1}$ and $A_{3}$ are the factors more different from unity for the three materials).

Finally, the universal anisotropy index, ${ }^{63}$

$$
A^{U}=5\left(\frac{G_{V}}{G_{R}}\right)+\left(\frac{B_{V}}{B_{R}}\right)-6
$$

was obtained. In this expression, $G_{V}$ and $G_{R}$ are the values of the shear modulus in the Voigt and Reuss schemes and $G_{V}$ and $G_{R}$ are the values of the bulk modulus in the same approximations. The departure of $A^{U}$ from zero defines the extent of single-crystal anisotropy and accounts for both the shear and the bulk contributions unlike all other existing anisotropy measures. $A^{U}$ is independent of the scheme used to determine the polycrystalline elastic properties because it is defined in terms of the bulk and shear moduli in both Voigt and Reuss approximations. ${ }^{63}$ For the three materials considered, the computed universal anisotropy was quite large (see Table 5). The precise values were 4.6, 2.4, and 12.4 for oxalic acid dihydrate and the $\alpha$ and $\beta$ polymorphic forms of anhydrous oxalic acid, respectively. This large anisotropy is in agreement with the large difference between the values of the elastic constants along the different directions and derives directly from the differences in bonding strength between the atoms belonging to the unit cells of these materials along the different directions. In the cases of oxalic acid dihydrate and the $\alpha$ polymorphic form of anhydrous oxalic acid the bonding in the direction perpendicular to the layers characterizing their structures is very weak. The same occurs for $\beta$-oxalic acid in the two directions orthogonal to the direction of propagation of the chains.

\subsubsection{Bulk modulus derivatives}

Lattice volumes around the optimized structures of these materials were calculated by optimizing the structures at 18 different applied isotropic pressures in the range -1.0 to 12.0 $\mathrm{GPa}$. Then, the calculated pressure-volume data were fitted to a fourth-order Birch-Murnaghan equation of state ${ }^{145}$ using the EOSFIT 5.2 program. ${ }^{146}$ The fit produces the best possible values of the parameters in the EOS. These parameters include the bulk modulus and their first and second derivatives with respect to pressure at the temperature of $0 \mathrm{~K}$. The results are shown in Table 6, where they are compared with the results obtained for the polycrystalline bulk modulus obtained from the elastic constants in the Reuss approximation. The bulk moduli obtained in both approaches agree satisfactorily.

\subsubsection{Anomalous mechanical properties}

\subsection{4.a Oxalic acid dihydrate}

\subsection{4.a.i Negative Poisson ratio}

Tridimensional representations of the most important elastic properties for oxalic acid dihydrate were obtained using EIAM software 65 and are displayed in Fig. 4. For the case of the shear modulus and Poisson ratios, depending on two directions, Figs. 4.C and Fig. 4.D provide representations of surfaces of maximum $\boldsymbol{G}$ and $\boldsymbol{v}$, respectively, that is, the surface formed with the maximum values of these properties for the given direction of the longitudinal strain and all possible transverse directions. ${ }^{65}$ For the oxalic acid dihydrate, the surface of minimum Poison ratio, displayed in Fig. 5.A, shows that this material is an NPR compound with a value of the lowest Poisson ratio of -0.24 (see Table 7 ).

Table 3. Computed elastic constants for oxalic acid dihydrate and anhydrous oxalic acid ( $\alpha$ and $\beta$ polymorphs).

\begin{tabular}{cccc}
\hline \multirow{i}{*}{$\boldsymbol{j}$} & \multicolumn{3}{c}{$\boldsymbol{C}_{\boldsymbol{i j}}$} \\
\cline { 2 - 4 } & $\begin{array}{c}\text { Oxalic acid } \\
\text { dihydrate }\end{array}$ & $\boldsymbol{\alpha}$-Oxalic acid & $\boldsymbol{\beta}$-Oxalic acid \\
\hline 11 & 34.12 & 31.05 & 132.03 \\
22 & 13.97 & 46.65 & 19.49 \\
33 & 51.87 & 27.55 & 17.73 \\
44 & 4.34 & 42.64 & 15.56 \\
55 & 18.90 & 11.85 & 30.61 \\
66 & 16.00 & 8.23 & 6.02 \\
12 & 12.70 & 17.44 & 1.49 \\
13 & 17.47 & 13.49 & 29.65 \\
15 & 2.18 & 0.00 & -55.16 \\
23 & 8.14 & 14.22 & 9.32 \\
25 & -2.16 & 0.00 & 1.31 \\
35 & 12.95 & 0.00 & -11.52 \\
46 & -2.75 & 0.00 & 1.36 \\
\hline
\end{tabular}

Table 4. Computed mechanical properties for oxalic acid dihydrate and anhydrous oxalic acid ( $\alpha$ and $\beta$ polymorphs). The values of the bulk, shear and Young moduli ( $B, G$ and $E$, respectively) are given in in GPa.

\begin{tabular}{cccc}
\hline Property & $\begin{array}{c}\text { Oxalic acid } \\
\text { dihydrate }\end{array}$ & $\boldsymbol{\alpha}$-Oxalic acid & $\boldsymbol{\beta}$-Oxalic acid \\
\hline $\boldsymbol{B}$ & 12.81 & 20.42 & 11.57 \\
$\boldsymbol{G}$ & 6.56 & 11.26 & 5.91 \\
$\boldsymbol{E}$ & 16.82 & 28.53 & 15.16 \\
$\boldsymbol{v}$ & 0.28 & 0.27 & 0.28 \\
$\boldsymbol{D}$ & 1.95 & 1.81 & 1.96 \\
$\boldsymbol{H}$ & 0.25 & 1.11 & 0.42 \\
\hline
\end{tabular}


Table 5. Computed anisotropy factors for oxalic acid dihydrate and anhydrous oxalic acid ( $\alpha$ and $\beta$ polymorphs).

\begin{tabular}{cccc}
\hline Factor & $\begin{array}{c}\text { Oxalic acid } \\
\text { dihydrate }\end{array}$ & $\boldsymbol{\alpha}$-Oxalic acid & $\boldsymbol{\beta}$-Oxalic acid \\
\hline $\boldsymbol{A}_{\mathbf{1}}$ & 0.34 & 5.39 & 0.69 \\
$\boldsymbol{A}_{\mathbf{2}}$ & 1.54 & 1.04 & 6.59 \\
$\boldsymbol{A}_{\mathbf{3}}$ & 2.90 & 0.77 & 0.16 \\
$\boldsymbol{A}^{\boldsymbol{U}}$ & 4.60 & 2.41 & 12.49 \\
\hline
\end{tabular}

Table 6. Computed bulk modulus and pressure derivatives derived from the EOS for oxalic acid dihydrate and anhydrous oxalic acid ( $\alpha$ and $\beta$ polymorphs). The values of the bulk modulus computed from the elastic constants are given in the last row of the table for comparison.

\begin{tabular}{cccc}
\hline Property & Oxalic acid dihydrate & $\alpha$-Oxalic acid & $\beta$-Oxalic acid \\
\hline \multicolumn{4}{c}{ EOS } \\
\hline $\boldsymbol{B}(\mathrm{GPa})$ & $12.41 \pm 0.81$ & $16.85 \pm 0.29$ & $12.64 \pm 0.25$ \\
$\boldsymbol{B}^{\prime}$ & $9.38 \pm 1.18$ & $5.64 \pm 0.37$ & $7.30 \pm 0.41$ \\
$\boldsymbol{B}^{\prime \prime}\left(\mathrm{GPa}^{-1}\right)$ & $-3.49 \pm 1.83$ & $-0.1 \pm 0.24$ & $-0.53 \pm 0.45$ \\
$\boldsymbol{X} \mathbf{C}$ & 0.075 & 0.002 & 0.004 \\
\hline \multicolumn{4}{c}{ Elastic constants } \\
\hline $\boldsymbol{B}(\mathrm{GPa})$ & $12.81 \pm 0.41$ & $20.42 \pm 0.79$ & $11.57 \pm 0.26$ \\
\hline
\end{tabular}

3.3.4.a.ii Lattice parameters and X-ray powder diffraction pattern as a function of the applied pressure

In order to understand the structural variations produced by the application of pressure in oxalic acid dihydrate, the structure of this material was optimized under the effect of different pressures applied along the direction of the minimum Poisson ratio (given in Table 7). The lattice parameters and volumes obtained for fourteen applied pressures along this direction are reported in Table 8. The corresponding X-ray powder diffraction patterns were determined from the optimized structures and six of these patterns are displayed in Fig. 6 . The displacements of the main reflections in the X-Ray pattern of oxalic acid dihydrate due to the effect of the applied pressures are collected in Table S5 of the Supplementary Information.

The system is compressed along $U_{\min }^{L}$ for positive pressures and the unit cell volume decreases accordingly. However, for positive applied pressures larger than $0.2503 \mathrm{GPa}$, the volume begins to increase, that is, oxalic acid dihydrate exhibits the NLC phenomenon. Similarly, the material expands for negative pressures, but undergoes a phase transition at a pressure of about $-0.045 \mathrm{GPa}$. Thus, oxalic acid dihydrate displays anomalous mechanical behavior at positive and negative pressures applied in this direction. The pressure induced phase is described below.

As can be seen in Table S5, the parameter $d$ of the main [-1- 11] and other reflections decrease as the applied positive pressure increases (or, equivalently, the corresponding $2 \theta$ values increase). The [011] reflection is the one with larger negative variation. There are also many reflections which displace towards larger $d$, notably [100], [-102], and [202]. The displacement of [100] reflection is due to the increase of $a$ lattice parameter. The [100] reflection exhibits a very large displacement towards large $d$ (or towards smaller $2 \theta$, see the Figure 5) from $\mathrm{P}=0.2803 \mathrm{GPa}$, leading to the NLC phenomenon. Therefore, the anomalously large increase of $a$ lattice parameter when the pressure increases from $P=0.250 \mathrm{GPa}$ is the origin of the NLC in oxalic acid dihydrate.
A

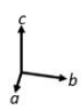

B

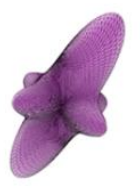

C

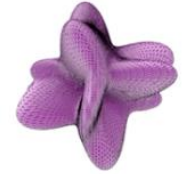

D

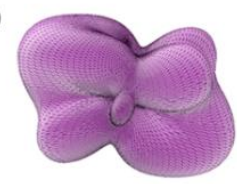

Figure. 4. Elastic properties of oxalic acid dihydrate as a function of the orientation of the applied strain: (A) Compressibility; (B) Young modulus; (C) Maximum shear modulus; (D) Maximum Poisson ratio.
A

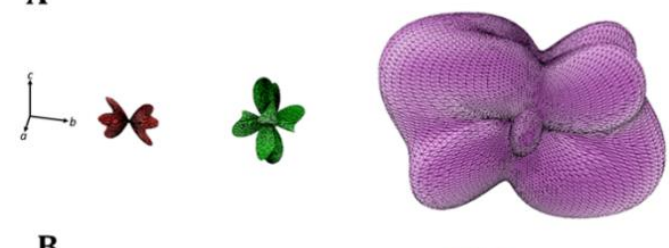

B
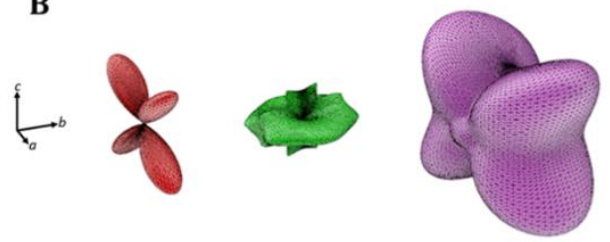

C

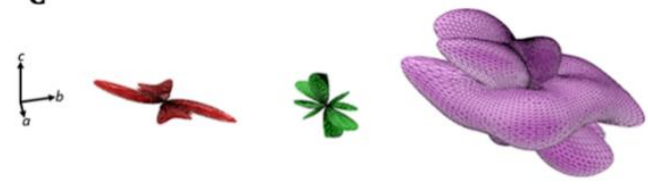

Figure 5. Computed surfaces of minimum, average, and maximum Poisson ratio of oxalic acid dihydrate (A), $\alpha$-oxalic acid (B), and $\beta$ oxalic acid (C).

\subsection{4.a.iii Crystal structure deformation}

Table 9 reports the values of selected interatomic distances between the atoms in the structure of oxalic acid dihydrate. As can be seen, for example from the first two columns of the table, the bond distances within the oxalic acid molecules in the crystal, change only very slightly under the effect of the applied pressures. The main changes arising from the application of pressure are the diminution and increase of the distances between hydrogen bonded oxalic acid molecule units along $c$ and $a$ directions, respectively (see the $\mathrm{C}^{-}-\mathrm{O}^{\prime}$ and $\mathrm{O} 2-\mathrm{C2}^{\prime}$ distances in Table 9, where the atoms marked with a prime belong to contiguous oxalic acid molecules placed in the $c$ and $a$ directions, respectively), and the decrease of the non-bonding distances between the molecules along $b$ direction (see the C1C1* distances in Table 9, where the $\mathrm{C} 1$ and $\mathrm{C} 1 *$ atoms are placed in two parallel non-bonded oxalic acid molecules; see Figure S1 of Supplementary Information). 


\section{PCCP}

\section{PAPER}

Table 7. Minimum and maximum Poisson ratios in oxalic acid dihydrate and anhydrous oxalic acid ( $\alpha$ and $\beta$ polymorphs). The directions for the associated longitudinal and transverse directions are also given.

\begin{tabular}{|c|c|c|c|c|c|}
\hline $\boldsymbol{v}_{\min }$ & $\boldsymbol{U}_{\min }^{L}$ & $U_{\min }^{T}$ & $v_{\max }$ & $U_{\max }^{L}$ & $U_{\max }^{T}$ \\
\hline \multicolumn{6}{|c|}{ Oxalic acid dihydrate } \\
\hline-0.24 & $(0.68,-0.61,-0.40)$ & $(0.73,0.56,0.39)$ & 1.01 & $(-0.88,0.00,0.47)$ & $(0.00,-1.00,0.00)$ \\
\hline \multicolumn{6}{|c|}{$\alpha$-Oxalic acid } \\
\hline-0.45 & $(0.01,-0.73,-0.68)$ & $(-0.01,0.68,-0.73$ & 0.71 & $(0.01,-0.78,0.63)$ & $(1.00,0.02,0.00)$ \\
\hline \multicolumn{6}{|c|}{$\beta$-Oxalic acid } \\
\hline-0.60 & $(0.95,0.00,-0.31)$ & $(0.00,1.00,0.00)$ & 1.04 & $(-0.97,0.00,0.25)$ & $(-0.25,0.00,-0.97)$ \\
\hline
\end{tabular}

Table 8. Computed lattice parameters and volumes in the oxalic acid dihydrate at different applied pressures directed along the direction of minimum Poisson ratio.

\begin{tabular}{cccccc}
\hline $\mathbf{P}(\mathbf{G P a})$ & $\boldsymbol{a}(\mathbf{\AA})$ & $\boldsymbol{b}(\AA)$ & $\boldsymbol{c}(\AA)$ & $\boldsymbol{\beta}(\mathbf{d e g})$ & Vol. $\left(\AA^{3}\right)$ \\
\hline-0.1269 & 2.9297 & 6.6210 & 12.2466 & 98.968 & 234.6530 \\
-0.0510 & 3.0099 & 6.5584 & 11.6744 & 96.440 & 229.0023 \\
-0.0389 & 5.9167 & 3.6476 & 11.6523 & 104.137 & 243.8587 \\
0.0 & 6.0321 & 3.5360 & 11.5719 & 104.138 & 239.3514 \\
0.0297 & 6.0817 & 3.4953 & 11.5891 & 104.365 & 238.6498 \\
0.0465 & 6.1654 & 3.4175 & 11.5625 & 104.461 & 235.9050 \\
0.1005 & 6.2261 & 3.3720 & 11.5392 & 104.510 & 234.5281 \\
0.1387 & 6.3500 & 3.2976 & 11.5033 & 104.571 & 233.1250 \\
0.1614 & 6.3983 & 3.2703 & 11.4752 & 104.526 & 232.4373 \\
0.1768 & 6.4587 & 3.2409 & 11.4521 & 104.530 & 232.0478 \\
0.2123 & 6.5030 & 3.2207 & 11.4289 & 104.564 & 231.6727 \\
0.2658 & 6.5532 & 3.1918 & 11.3997 & 104.430 & 230.9190 \\
0.2803 & 6.6213 & 3.1733 & 11.3716 & 104.465 & 231.3592 \\
0.3269 & 6.8206 & 3.1243 & 11.2785 & 103.103 & 234.0854 \\
\hline
\end{tabular}

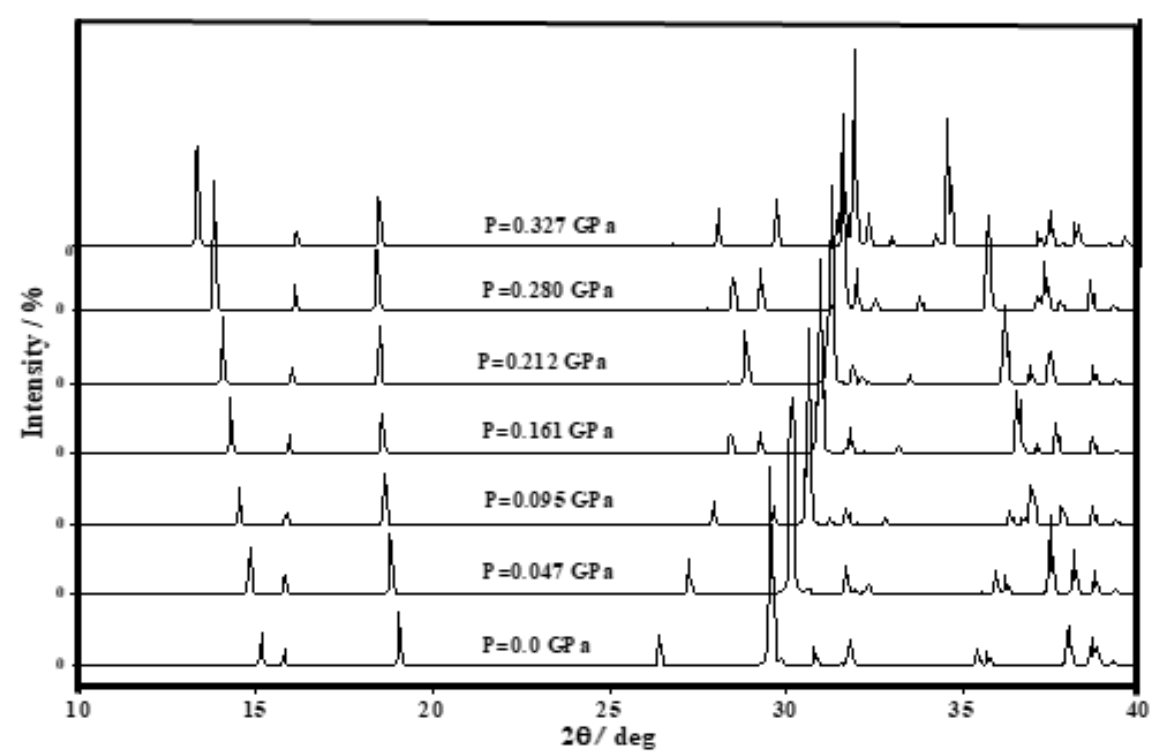

Figure. 6. X-ray powder diffraction pattern for oxalic acid dihydrate as a function of the applied pressure. 
Table 9. Selected interatomic distances (in $\AA$ ) in oxalic acid dihydrate at different applied pressures directed along $U_{\min }^{L}$. The symbol $\Delta$ in the table refers to the variation of the bond distances at $\mathrm{P}=0.266 \mathrm{GPa}$ with respect to those at $\mathrm{P}=0 \mathrm{Gpa}$. Similarly, the symbol $\Delta^{\prime}$ in the table refers to the variation of the bond distances at $\mathrm{P}=0.327 \mathrm{GPa}$ with respect to those at $\mathrm{P}=0.280 \mathrm{GPa}$.

\begin{tabular}{|c|c|c|c|c|c|c|c|}
\hline $\mathrm{P}(\mathrm{GPa})$ & 01-C1 (R1) & C1-O2 (R3) & C1-C1* & C1-01' (R2) & O2-C2' (R4) & R1+R2 & R3+R4 \\
\hline-0.039 & 1.285 & 1.242 & 3.648 & 10.457 & 4.949 & 11.742 & 6.191 \\
\hline 0.0 & 1.286 & 1.241 & 3.536 & 10.376 & 5.044 & 11.662 & 6.285 \\
\hline 0.030 & 1.286 & 1.241 & 3.495 & 10.390 & 5.087 & 11.676 & 6.328 \\
\hline 0.047 & 1.287 & 1.241 & 3.418 & 10.361 & 5.159 & 11.648 & 6.4 \\
\hline 0.101 & 1.287 & 1.240 & 3.372 & 10.335 & 5.213 & 11.622 & 6.453 \\
\hline 0.139 & 1.289 & 1.239 & 3.298 & 10.295 & 5.318 & 11.584 & 6.557 \\
\hline 0.161 & 1.289 & 1.239 & 3.270 & 10.265 & 5.360 & 11.554 & 6.599 \\
\hline 0.177 & 1.290 & 1.238 & 3.241 & 10.240 & 5.414 & 11.53 & 6.652 \\
\hline 0.212 & 1.290 & 1.238 & 3.221 & 10.215 & 5.453 & 11.505 & 6.691 \\
\hline 0.266 & 1.290 & 1.238 & 3.192 & 10.183 & 5.495 & 11.473 & 6.733 \\
\hline 0.280 & 1.291 & 1.237 & 3.173 & 10.153 & 5.561 & 11.444 & 6.798 \\
\hline 0.327 & 1.295 & 1.235 & 3.124 & 10.057 & 5.747 & 11.352 & 6.982 \\
\hline$\Delta$ & +0.004 & -0.003 & -0.344 & -0.193 & +0.451 & -0.189 & +0.488 \\
\hline$\Delta^{\prime}$ & +0.004 & -0.002 & -0.049 & -0.096 & +0.186 & -0.092 & +0.184 \\
\hline
\end{tabular}

Table 10. Lattice parameters of the pressure induced phase of oxalic acid dihydrate.

\begin{tabular}{ccccccc}
\hline Parameter & $\boldsymbol{a}(\AA)$ & $\boldsymbol{b}(\AA)$ & $\boldsymbol{c}(\AA)$ & $\boldsymbol{\beta}(\mathbf{d e g})$ & Vol. $\left(\AA^{3}\right)$ & Dens. $\left(\mathbf{g} / \mathrm{cm}^{3}\right)$ \\
\hline DFT $(\mathrm{P}=-0.051 \mathrm{GPa})^{a}$ & 3.0099 & 6.5584 & 11.6744 & 96.440 & 229.0023 & 1.829 \\
$\mathrm{DFT}(\mathrm{P}=-0.127 \mathrm{GPa})^{b}$ & 2.9297 & 6.6210 & 12.2466 & 98.968 & 234.6530 & 1.785 \\
\hline \multicolumn{6}{c}{$\mathrm{P}=(0.526,-0.386,-0.292)$} & $\mathrm{GPa} ;{ }^{b} \mathrm{P}=(0.672,-0.644,-0.409)$
\end{tabular}

The diminution of the distance between the non-bonded oxalic acid molecules is the responsible of the change in $b$ lattice parameter $(+0.34 \AA)$. The variation of the relative distances between the oxalic acid molecules along the $a, b$ and $c$ directions results in the simultaneous decrease of the sizes of the unit cell along $U_{\min }^{L}$ and $U_{\min }^{T}$. Therefore, oxalic acid dihydrate shrinks laterally when compressed and display NPR values. Within the pressure range from 0 to $0.250 \mathrm{GPa}$, these variations lead to the expected reduction of the unit cell volume. However, for larger applied pressures the volume increases due to the much larger increase of the distances between the oxalic acid molecules along $a$ direction which is not counter balanced by the decrease of the $b$ and $c$ lattice parameters. This leads to the NLC in oxalic acid dihydrate for applied pressures of about $0.25 \mathrm{GPa}$ directed along $U_{\text {min }}^{L}$ direction.

\subsection{4.a.iv Pressure induced phase transition}

As shown in a previous subsection, oxalic acid dihydrate undergoes a pressure induced phase transition under the effect of negative pressures directed along the $(0.68,-0.61,-0.40)$ direction. The crystal space symmetry of this phase is monoclinic, space group $P 12_{1} / \mathrm{c} 1$. The computed lattice parameters, cell volume and density associated to this phase for two different applied pressures is shown in Table 10 Furthermore, images of the corresponding unit cell from [010] and [110] directions are displayed in Fig. 7.

\subsection{4.b $\alpha$-Oxalic acid}

\subsection{4.b.i Negative Poisson ratio}

The representations of the most important elastic properties of $\alpha$-oxalic acid are shown in Fig. 8. Similarly, the representation of the surfaces of minimum, average and maximum Poisson ratios are displayed in Fig. 5.B, where it is shown that $\alpha$-oxalic acid is, as oxalic acid dihydrate, an NPR material. The value of the lowest Poisson ratio is much larger than for oxalic acid dihydrate $(-0.45$, see Table 11$)$ 3.3.4.b.ii Lattice parameters and X-ray powder diffraction pattern as a function of the applied pressure

The lattice parameters and volumes obtained for eighteen different applied pressures along the direction of the minimum Poisson ratio are reported in Table 11 . The corresponding X-ray powder diffraction patterns of $\alpha$-oxalic acid at six different pressures are displayed in Fig. 9. The displacements of the main reflections in the X-Ray pattern due to the effect of the applied pressures are shown in Table S6 of the Supplementary Information.

For positive pressures from $\mathrm{P}=0.0$ to $\mathrm{P}=1.3684 \mathrm{GPa}$ applied along $U_{\text {min }}^{L}=(0.01,-0.73,-0.68)$ direction, the volume decreases properly as does the length along this direction. However, the length along the transverse direction decreases instead of increasing, that is, the material shrinks laterally when compressed. For negative pressures the material laterally expands when stretched. For applied pressures larger than $1.3684 \mathrm{GPa}$, the volume increases, that is, the system exhibits the NLC phenomenon. However, the volume then decreases at about $\mathrm{P}=1.63 \mathrm{GPa}$ and increases again at about $\mathrm{P}=1.80 \mathrm{GPa}$. This irregular behavior of the material under compression is due to the vicinity of a phase transition which occurs at a pressure of about $1.91 \mathrm{GPa}$. From this pressure, the material undergoes a monoclinic distortion, but the space symmetry of the new most stable phase has also orthorhombic Pbca space symmetry from $\mathrm{P}=2.79 \mathrm{GPa}$.

The parameter $d$ of the main [111] reflection decrease as expected from the increase of the applied external pressure. The [022] reflection maps approximately the decrease of the distance along the minimum Poisson ratio direction. Similarly, the [012], which is also one of the strongest reflections with negative variations, map the simultaneous decrease of $b$ and $c$ lattice parameters. The decrease of the reflections [020] and [040] map the decrease of $b$ lattice parameter and the [004] reflection map the decrease of $c$ lattice parameter. There are 
also many reflections which displace towards larger $d$ (smaller $2 \theta$ ); The increase of the $d$ parameter for [200] reflection maps directly the increase of the $a$ lattice parameter.

As can readily be seen in Fig. 9, at pressures larger than about $1.9 \mathrm{GPa}$ applied along $U_{\min }^{L}$ direction, the X-ray diffraction patterns of $\alpha$ - oxalic acid become completely different to those at lower pressures due to the occurrence of the phase transition.

\subsection{4.b.iii Crystal structure deformation}

As can be seen, from the two first two columns of Table 12, where the variations of the $\mathrm{C} 1-\mathrm{O} 1$ and $\mathrm{C} 1-\mathrm{O} 2$ distances are shown, the bond distances within the oxalic acid molecules in the crystal, change only very slightly under the applied pressures. The main changes arising from the application of pressure are the diminution of the distances between oxalic acid molecule units along $b$ and $c$ directions, respectively (see the C1-C1' and C1-C2" distances in Table 12, where the atoms marked with a prime belong to contiguous oxalic acid molecules placed in the $b$ and $a$ directions, respectively) and the increase of the non-bonding distances between the molecules along $a$ direction (see the $\mathrm{C} 1^{*}-\mathrm{C} 1^{* *}$ distances in Table 12 , where the $\mathrm{C} 1^{*}$ and $\mathrm{C} 1^{*}$ atoms are placed in two parallel non-bonded oxalic acid molecules, belonging to one sheet at the right and one sheet at the left of a central sheet, see Figure S2 of the Supplementary Information). The $\mathrm{C}^{*}-\mathrm{C} 1^{* *}$ distance is two times the interlayer space.

The diminution of the distances between the oxalic acid molecules within the sheets are the responsible of the change in $b$ and $c$ lattice parameters ( -0.31 and $-0.38 \AA$, respectively), and the increase of the distances between the oxalic acid molecules in two different sheets is the responsible of the change in $a$ lattice parameter $(+0.49 \mathrm{~A})$. While our main interest is the description of the variation of the distances in the $\{011\}$ plane ( $\boldsymbol{U}_{\text {min }}^{\boldsymbol{L}}$ and $\boldsymbol{U}_{\text {min }}^{\boldsymbol{T}}$ are contained in this plane), the changes in $a$ lattice parameter, or equivalently the distance between the folded sheets, should be taken into account because they serve to accomodate the structure under pressure. Accompanied with the decrease of the distance between the molecules along $U_{\text {min }}^{L}$ direction originated by the application of pressure, there is also a decrease in the distances between molecules placed perpendicularly to the first ones within the sheets which leads to the NPR. The larger increase of the distance between the sheets, which is not compensated by the smaller decrease of the distances in $\{011\}$ plane, is the reason of the NLC at pressures between $\mathrm{P}=1.37$ and $1.73 \mathrm{GPa}$. The tendency towards a smaller increase in the distances in the $\{011\}$ plane is due to the proximity of the phase transition because the new phase has larger $b$ and $c$ lattice parameters and a very different crystal structure.

\subsection{4.b.iv Pressure induced phase transition}

$\alpha$-Oxalic acid undergoes a pressure induced phase transition under the effect of an applied pressure directed along the $(0.01$, $-0.73,-0.68)$ direction. The crystal space symmetry of this phase is orthorhombic, space group Pbca. The computed lattice parameters, cell volume and density associated to this phase for an applied pressure of $\mathrm{P}=2.790 \mathrm{GPa}$ are shown in Table 13. Furthermore, images of the corresponding unit cell from [001], [100], and [010] directions are displayed in Fig. 10.
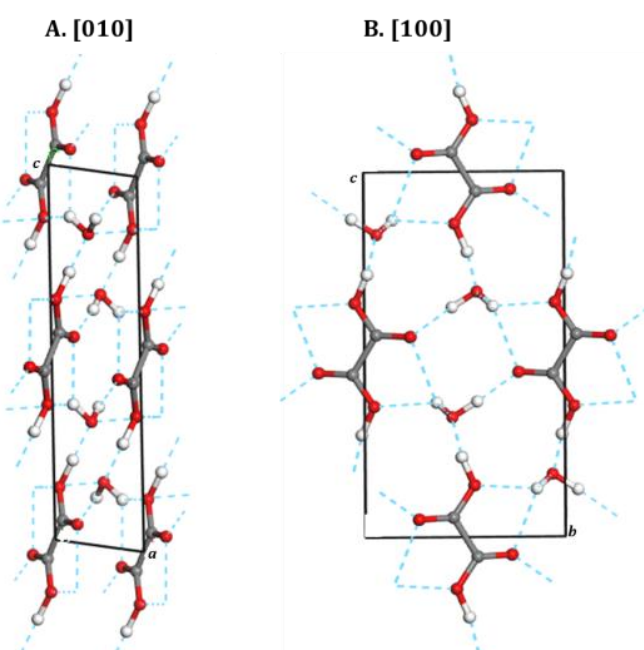

Figure 7. Views of the unit cell of the pressure induced phase of oxalic acid dihydrate at $\mathrm{P}=-0.127 \mathrm{GPa}$ from [010] (A) and [100] (B) directions.

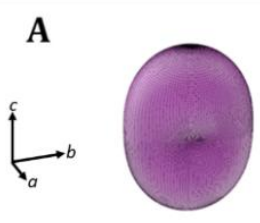

B

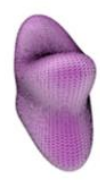

C

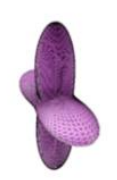

D

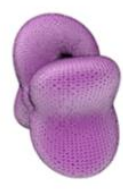

Figure. 8. Elastic properties of $\alpha$-oxalic acid as a function of the orientation of the applied strain: (A) Compressibility; (B) Young modulus; (C) Maximum shear modulus; (D) Maximum Poisson ratio. 


\section{PCCP}

\section{PAPER}

Table 11. Computed lattice parameters and volumes of $\alpha$-oxalic acid at different applied pressures directed along $U_{m i n}^{L}$ direction.

\begin{tabular}{ccccc}
\hline $\mathbf{P}(\mathbf{G P a})$ & $\mathbf{a}(\mathbf{\AA})$ & $\mathbf{b}(\AA)$ & $\mathbf{c}(\AA)$ & $\mathbf{V} \mathbf{l} .(\mathbf{(} \mathbf{3})$ \\
\hline-0.4464 & 6.5313 & 7.6634 & 6.3134 & 315.9994 \\
-0.2239 & 6.6088 & 7.6299 & 6.2079 & 313.0341 \\
0.0 & 6.6263 & 7.6105 & 6.1397 & 309.6211 \\
0.2204 & 6.6659 & 7.5792 & 6.0769 & 307.0158 \\
0.4553 & 6.7550 & 7.5320 & 5.9973 & 305.1327 \\
0.6911 & 6.8348 & 7.4653 & 5.9446 & 303.3163 \\
0.9590 & 6.9213 & 7.4072 & 5.8819 & 301.5467 \\
1.1614 & 7.0309 & 7.3566 & 5.8136 & 300.7032 \\
1.2844 & 0.0322 & -2.0204 & 5.7785 & 300.3796 \\
1.4113 & 7.1192 & 7.2978 & 5.7607 & 299.2925 \\
1.5133 & 7.2315 & 7.2655 & 5.7089 & 299.9510 \\
1.6212 & 7.3264 & 7.2229 & 5.6688 & 299.9796 \\
1.7245 & 7.4272 & 7.1779 & 5.6252 & 299.8865 \\
1.8700 & 7.4969 & 7.1457 & 5.5981 & 299.8938 \\
1.9494 & 9.5179 & 6.4781 & 4.9423 & 304.7349 \\
2.1014 & 10.2764 & 4.6194 & 5.8688 & 278.5682 \\
2.3446 & 10.4588 & 4.4858 & 6.1538 & 269.1763 \\
2.7895 & 10.2728 & 4.5864 & 5.7744 & 272.0564 \\
\hline
\end{tabular}

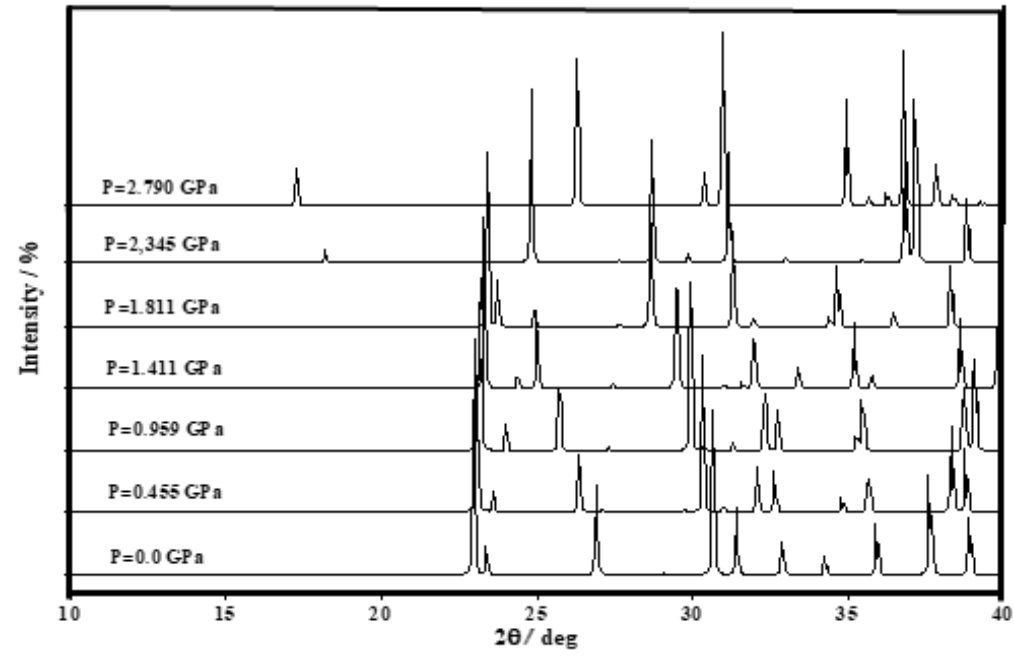

Figure. 9. X-ray powder diffraction pattern for $\alpha$-oxalic acid as a function of the applied pressure.

A. [001]

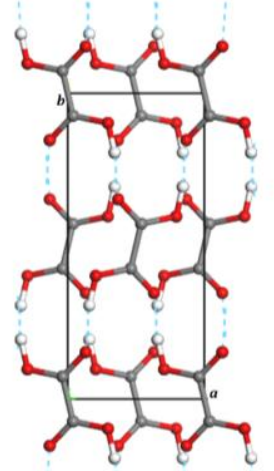

B. [100]

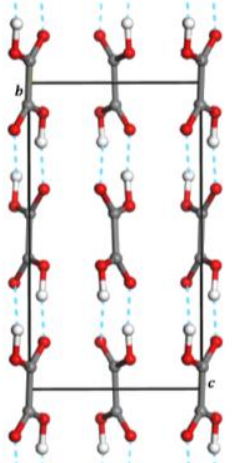

c. [010]

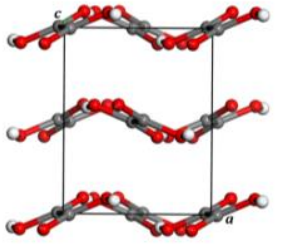

Figure 10. Views of the unit cell of the pressure induced phase of $\alpha$-oxalic acid at P=2.790 GPa from [001] (A), [100] (B), and [010] (C) directions. 
Table 12. Selected interatomic distances (in $\AA$ ) in $\alpha$-oxalic acid at different applied pressures directed along $U_{\min }^{L}$. The symbol $\Delta$ in the table refers to the variation of the bond distances at $\mathrm{P}=1.411 \mathrm{GPa}$ with respect to those at $\mathrm{P}=0 \mathrm{GPa}$. The symbol $\Delta^{\prime}$ in the table refers to the variation of the distances at $P=1.621 \mathrm{GPa}$ with respect to those at $\mathrm{P}=1.513 \mathrm{GPa}$. Finally, $\Delta^{\prime \prime}$ refers to the variation of the distances at $\mathrm{P}=1.870 \mathrm{GPa}$ with respect to those at $\mathrm{P}=1.725 \mathrm{GPa}$.

\begin{tabular}{cccccc}
\hline P(GPa) & C1-O1 & C1-O2 & O1*-O1** $^{*}$ C1-C1' & C1-C2"' \\
\hline-0.464 & 1.309 & 1.224 & 6.531 & 7.663 & 6.313 \\
-0.224 & 1.308 & 1.225 & 6.609 & 7.630 & 6.208 \\
0.0 & 1.307 & 1.225 & 6.626 & 7.611 & 6.140 \\
0.220 & 1.305 & 1.226 & 6.666 & 7.579 & 6.077 \\
0.455 & 1.305 & 1.226 & 6.755 & 7.532 & 5.997 \\
0.691 & 1.303 & 1.227 & 6.835 & 7.465 & 5.945 \\
0.959 & 1.302 & 1.227 & 6.921 & 7.407 & 5.882 \\
1.161 & 1.301 & 1.228 & 7.031 & 7.357 & 5.814 \\
1.284 & 1.300 & 1.228 & 7.109 & 7.312 & 5.779 \\
1.411 & 1.300 & 1.228 & 7.119 & 7.298 & 5.761 \\
1.513 & 1.299 & 1.229 & 7.232 & 7.266 & 5.709 \\
1.621 & 1.299 & 1.229 & 7.326 & 7.223 & 5.669 \\
1.725 & 1.299 & 1.229 & 7.427 & 7.178 & 5.625 \\
1.870 & 1.298 & 1.229 & 7.497 & 7.146 & 5.598 \\
1.949 & 1.310 & 1.225 & 4.492 & 9.518 & 6.478 \\
2.101 & 1.304 & 1.226 & 5.869 & 10.275 & 4.619 \\
2.345 & 1.303 & 1.226 & 6.154 & 10.459 & 4.486 \\
2.790 & 1.303 & 1.225 & 5.744 & 10.273 & 4.586 \\
$\Delta$ & -0.007 & 0.003 & 0.493 & -0.313 & -0.379 \\
$\Delta^{\prime}$ & 0.000 & 0.000 & +0.094 & -0.043 & -0.040 \\
$\Delta^{\prime \prime}$ & -0.001 & 0.000 & +0.070 & -0.032 & -0.027 \\
\hline
\end{tabular}

Table 13. Lattice parameters of the pressure induced phase of $\alpha$-oxalic acid.

\begin{tabular}{ccccccccc}
\hline Parameter & a $(\AA)$ & $\mathbf{b}(\AA)$ & $\mathbf{c}(\AA)$ & $\boldsymbol{\alpha}$ & $\boldsymbol{\beta}$ & $\boldsymbol{\nu}$ & Vol. $\left(\AA^{3}\right)$ & Dens. $\left(\mathbf{g} / \mathbf{c m}^{3}\right)$ \\
DFT $(\mathrm{P}=2.7895 \mathrm{GPa})^{a}$ & 4.5864 & 10.2728 & 5.7744 & 90 & 90 & 90 & 272.0618 & 2.198 \\
\hline \multicolumn{7}{c}{$\mathrm{P}=(-0.076,4.378,-4.066) \mathrm{GPa}$}
\end{tabular}

\subsection{4.b.iii Crystal structure deformation}

As can be seen, from the two first two columns of Table 12, where the variations of the $\mathrm{C} 1-\mathrm{O} 1$ and $\mathrm{C} 1-\mathrm{O} 2$ distances are shown, the bond distances within the oxalic acid molecules in the crystal, change only very slightly under the applied pressures. The main changes arising from the application of pressure are the diminution of the distances between oxalic acid molecule units along $b$ and $c$ directions, respectively (see the C1-C1' and C1-C2" distances in Table 12, where the atoms marked with a prime belong to contiguous oxalic acid molecules placed in the $b$ and $a$ directions, respectively) and the increase of the non-bonding distances between the molecules along $a$ direction (see the $\mathrm{C}^{*}{ }^{*} \mathrm{C} 1^{* *}$ distances in Table 12 , where the $\mathrm{C}^{*}$ and $\mathrm{C}^{*}$ atoms are placed in two parallel non-bonded oxalic acid molecules, belonging to one sheet at the right and one sheet at the left of a central sheet, see Figure S2 of the Supplementary Information). The $\mathrm{C}^{*}-\mathrm{C} 1^{* *}$ distance is two times the interlayer space.

The diminution of the distances between the oxalic acid molecules within the sheets are the responsible of the change in $b$ and $c$ lattice parameters ( -0.31 and $-0.38 \AA$, respectively), and the increase of the distances between the oxalic acid molecules in two different sheets is the responsible of the change in $a$ lattice parameter $(+0.49 \mathrm{~A})$. While our main interest is the description of the variation of the distances in the $\{011\}$ plane ( $\boldsymbol{U}_{\text {min }}^{\boldsymbol{L}}$ and $\boldsymbol{U}_{\text {min }}^{\boldsymbol{T}}$ are contained in this plane), the changes in $a$ lattice parameter, or equivalently the distance between the folded sheets, should be taken into account because they serve to accomodate the structure under pressure. Accompanied with the decrease of the distance between the molecules along $U_{\text {min }}^{L}$ direction originated by the application of pressure, there is also a decrease in the distances between molecules placed perpendicularly to the first ones within the sheets which leads to the NPR. The larger increase of the distance between the sheets, which is not compensated by the smaller decrease of the distances in $\{011\}$ plane, is the reason of the NLC at pressures between $\mathrm{P}=1.37$ and $1.73 \mathrm{GPa}$. The tendency towards a smaller increase in the distances in the $\{011\}$ plane is due to the proximity of the phase transition because the new phase has larger $b$ and $c$ lattice parameters and a very different crystal structure.

\subsection{4.b.iv Pressure induced phase transition}

$\alpha$-Oxalic acid undergoes a pressure induced phase transition under the effect of an applied pressure directed along the $(0.01$, $-0.73,-0.68)$ direction. The crystal space symmetry of this phase is orthorhombic, space group $P$ bca. The computed lattice parameters, cell volume and density associated to this phase for an applied pressure of $\mathrm{P}=2.790 \mathrm{GPa}$ are shown in Table 13. Furthermore, images of the corresponding unit cell from [001], [100], and [010] directions are displayed in Fig. 10.

\subsection{4.c $\beta$-Oxalic acid}

\subsection{4.c.i Negative Poisson ratio}

The representations of the mechanical properties of the $\beta$ oxalic acid as a function of the strain orientation are shown in Fig. 11, and the surfaces of minimum, average and maximum Poisson ratios are displayed in Fig. 5.C. As shown in Fig. 5.C, $\beta$ oxalic acid is also an NPR material. The value of the minimum Poisson ratio of $\beta$-oxalic acid, -0.60 , is quite significant and the largest for the three considered materials. 
A

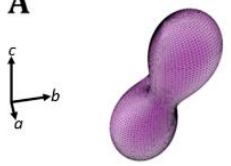

C

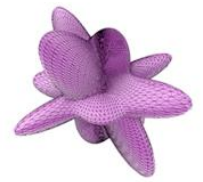

B

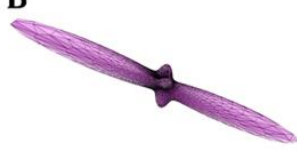

D

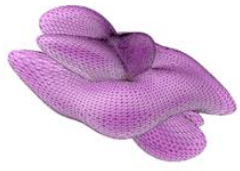

Figure 11. Elastic properties of $\beta$-oxalic acid as a function of the orientation of the applied strain: (A) Compressibility; (B) Young modulus; (C) Maximum shear modulus; (D) Maximum Poisson ratio.

Table 14. Computed lattice parameters and volumes of $\beta$-oxalic acid at different applied pressures directed along the direction of minimum Poisson ratio.

\begin{tabular}{cccccc}
\hline $\mathbf{P}(\mathrm{GPa})$ & $\mathbf{a}(\AA)$ & $\mathbf{b}(\AA)$ & $\mathbf{c}(\AA)$ & $\boldsymbol{\beta}(\mathbf{d e g})$ & $\mathbf{V o l} .\left(^{\mathbf{3}}\right)$ \\
\hline-0.3122 & 5.2983 & 6.3063 & 4.8748 & 106.656 & 156.0474 \\
-0.2718 & 5.2933 & 6.2545 & 4.9338 & 107.572 & 155.7209 \\
-0.2199 & 5.2880 & 6.2189 & 4.9878 & 108.757 & 155.3156 \\
-0.1788 & 5.2869 & 6.2060 & 5.0005 & 108.997 & 155.1322 \\
-0.1573 & 5.2877 & 6.0824 & 5.1786 & 112.270 & 154.1294 \\
0.0106 & 5.2743 & 5.9936 & 5.3998 & 114.755 & 155.0130 \\
0.0469 & 5.2698 & 5.9707 & 5.4905 & 116.961 & 153.9766 \\
0.1243 & 5.2693 & 5.9488 & 5.6129 & 119.196 & 153.5874 \\
0.1611 & 5.2607 & 5.9821 & 5.7200 & 120.595 & 154.9478 \\
0.2096 & 5.2551 & 6.0141 & 5.8339 & 122.252 & 155.9290 \\
0.2657 & 5.2703 & 9.1816 & 15.3097 & 167.532 & 159.9049 \\
0.4310 & 5.2868 & 9.3761 & 15.3193 & 168.097 & 156.5687 \\
\hline
\end{tabular}

3.3.4.c.ii Lattice parameters and X-ray powder diffraction pattern as a function of the applied pressure

The lattice parameters and volumes obtained for twelve different applied pressures along the direction of the minimum Poisson ratio are reported in Table 14. The corresponding X-ray powder diffraction patterns at six different pressures are displayed in Fig. 12. The displacements of the main reflections in the X-Ray powder pattern due to the effect of the applied pressures are collected in Table S7 of the Supplementary Information.

The system is compressed along $U_{\min }^{L}=(0.95,0.00,-0.31)$. As can be seen, for increasing pressures from $\mathrm{P}=0.0$ to $\mathrm{P}=0.0969$ $\mathrm{GPa}$ the volume decreases. However, for larger pressures the volume increases and therefore $\beta$-oxalic acid exhibits the NLC phenomenon. At pressures larger than of $\mathrm{P}=0.21 \mathrm{GPa}$, the material undergoes a phase transition due to a triclinic distortion of the monoclinic structure. The complete set of lattice parameters of the pressure induced phase will be given below (only a subset of these parameters is given in Table 14). For negative pressures, the cell volume should increase. However, the volume decreases initially until pressures of -0.05 $\mathrm{GPa}$ and then increases.

The parameter $d$ of the reflections [020] and [040] decrease as expected from the increase of the applied external pressure. The decrease of the parameter $d$ of these reflections maps directly the decrease of $b$ lattice parameter. However, the

position of these reflections increases between 0.124 and 0.210 GPa (see Table S7) due to the increase of this parameter, thus contributing to the rise of the volume characteristic of the NLC phenomenon. The parameter $d$ of the main [011] and other reflections increase (mainly due to the increase of $c$ lattice parameter. Other examples are the [-2-12], [-1-11] and [002] reflections. The [002] reflection maps directly the increase of the $c$ lattice parameter. For pressures higher than $0.21 \mathrm{GPa}$ (see Fig. 12), the X-ray diffraction pattern changes completely as a consequence of the phase transition.

\subsection{4.c.iii Crystal structure deformation}

As for oxalic acid dihydrate and $\alpha$-oxalic acid, the bond distances within the oxalic acid molecules in the crystal change only very slightly under the applied pressures because, for example, the variations of the $\mathrm{H} 1-\mathrm{O} 1$ and $\mathrm{O} 2-\mathrm{O} 1$ distances are small (Table 15). The main changes arising from the application of pressure are the diminution of the distances between hydrogen bonded oxalic acid molecule units placed within a chain directed along $a$ direction (see the $\mathrm{O} 1-\mathrm{H}_{1}$ ' distance in Table 15, where the atoms marked with a prime belong to contiguous oxalic acid molecules in a chain), and to a much larger extent the increase of the non-bonding distances between the oxalic molecules belonging to two different chains (see the $\mathrm{C} 1^{*}-\mathrm{C} 1^{* *}$ distances in Table 22 , where the $\mathrm{C} 1^{*}$ and $\mathrm{C} 1^{* *}$ atoms are placed in two parallel non-bonded oxalic acid molecules, belonging to one chain above and one chain below of a central chain; see Figure S3 of the Supplementary Information). The $\mathrm{C} 1^{*}-\mathrm{C} 1^{* *}$ distance is two times the interchain space, if we measure this space as $\mathrm{R}\left(\mathrm{C} 1-\mathrm{C} 1^{*}\right)$.

The diminution of the distances between the oxalic acid molecules within the chains is the responsible of the change in $a$ lattice parameter. The increase of the distances between the oxalic acid molecules in two different chains $(+0.215 \AA$ from $\mathrm{P}=-0.312 \mathrm{GPa}$ to $\mathrm{P}=-0.124 \mathrm{GPa}$ ) is reflected in the very large increase in $c$ lattice parameter $(+0.738 \AA)$ and the smaller decrease of the $b$ lattice parameter $(-0.356 \AA)$. However, at larger pressures, both parameters increase, the variation of the $c$ lattice parameter being very large $(0.221 \AA$ from $P=0.124$ to $0.210 \mathrm{GPa}$ ). This variation is responsible of the presence of negative linear compressibility at these pressures. From $P=0.21$ GPa a phase transition due to a triclinic distortion of the monoclinic crystal structure appears. For the new phase, while the variation of the distance of the molecules within the chains is small, the increase of the distances between the molecules in different chains is very extreme being about $2.591 \AA$ between $\mathrm{P}=0.431$ and $\mathrm{P}=0.210 \mathrm{GPa}$.

\subsection{4.c.iv Pressure induced phase transition}

$\beta$-Oxalic acid undergoes a pressure induced phase transition under the effect of an applied pressure directed along the 0.95 , $0.00,-0.31)$ direction. The crystal space symmetry of this phase is triclinic, space group $P 1$. The computed lattice parameters, cell volume and density associated to this phase for two applied pressures is shown in Table 16. Furthermore, images of the corresponding unit cell from [100], [010], and [001] directions are displayed in Fig. 13. 


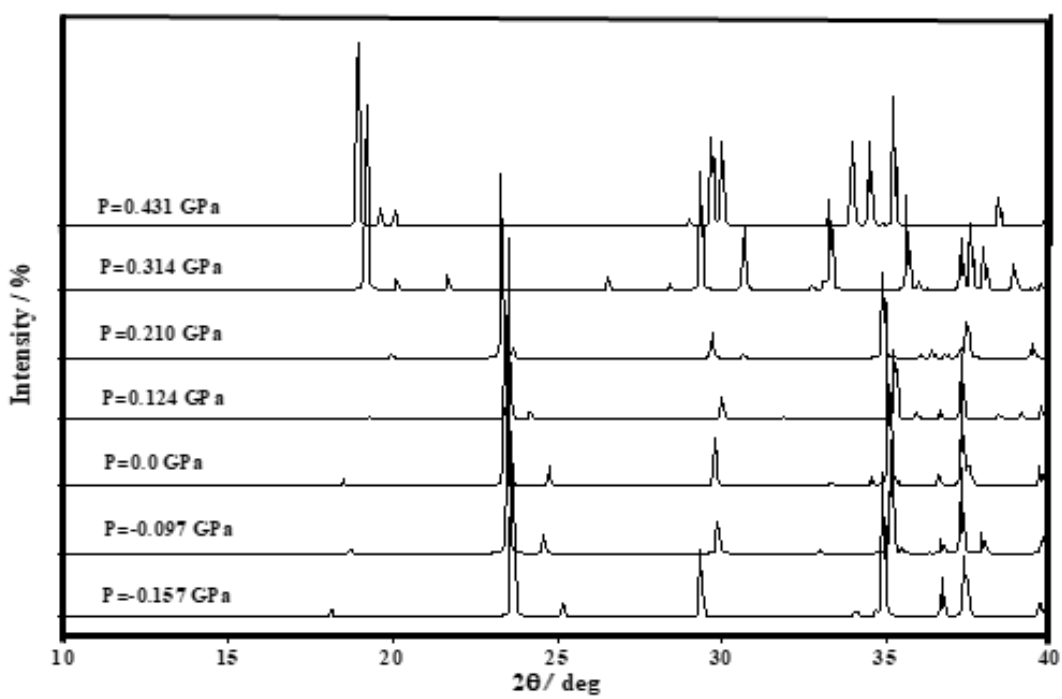

Figure. 12. X-ray powder diffraction pattern for $\beta$-oxalic acid as a function of the applied pressure.

Table 15. Selected bond distances (in $\AA$ ) in $\beta$-oxalic acid at different applied pressures directed along $U_{\min }^{L}$. The symbol $\Delta$ in the table refers to the variation of the bond distances at $\mathrm{P}=0.124 \mathrm{GPa}$ with respect to those at $\mathrm{P}=-0.312 \mathrm{GPa}$. The symbol $\Delta^{\prime}$ in the table refers to the variation of the distances at $P=0.210 \mathrm{GPa}$ with respect to those at $\mathrm{P}=0.124 \mathrm{GPa}$.

\begin{tabular}{|c|c|c|c|c|c|}
\hline $\mathrm{P}(\mathrm{GPa})$ & H1-01 (R1) & $02-01$ & $\mathrm{C} 1 *-\mathrm{C} 1 * *$ & $01 \cdots H 11^{\prime}(R 2)$ & $R 1+R 2$ \\
\hline-0.312 & 3.712 & 2.263 & 7.971 & 1.588 & 5.300 \\
\hline-0.272 & 3.711 & 2.263 & 7.966 & 1.584 & 5.295 \\
\hline-0.220 & 3.710 & 2.263 & 7.972 & 1.580 & 5.290 \\
\hline-0.179 & 3.709 & 2.264 & 7.970 & 1.580 & 5.289 \\
\hline-0.157 & 3.708 & 2.264 & 7.988 & 1.581 & 5.289 \\
\hline 0.0 & 3.707 & 2.263 & 8.067 & 1.569 & 5.276 \\
\hline 0.047 & 3.706 & 2.264 & 8.111 & 1.565 & 5.271 \\
\hline 0.124 & 3.701 & 2.265 & 8.186 & 1.569 & 5.270 \\
\hline 0.161 & 3.706 & 2.264 & 8.278 & 1.556 & 5.262 \\
\hline 0.210 & 3.705 & 2.265 & 8.375 & 1.551 & 5.256 \\
\hline 0.266 & 3.700 & 2.270 & 10.602 & 1.574 & 5.274 \\
\hline 0.431 & 3.696 & 2.270 & 10.966 & 1.597 & 5.293 \\
\hline$\Delta$ & -0.011 & +0.002 & +0.215 & -0.019 & -0.030 \\
\hline$\Delta^{\prime}$ & +0.004 & +0.000 & +0.189 & -0.018 & -0.014 \\
\hline
\end{tabular}

Table 16. Lattice parameters of the pressure induced phase of $\beta$-oxalic acid.

\begin{tabular}{|c|c|c|c|c|c|c|c|c|}
\hline Parameter & $a(\AA)$ & $b(\AA)$ & $c(\AA)$ & $\boldsymbol{\alpha}$ & $\beta$ & $\gamma$ & Vol. $\left(\AA^{3}\right)$ & Dens. $\left(\mathrm{g} / \mathrm{cm}^{3}\right)$ \\
\hline DFT $(P=0.2657 \mathrm{GPa})^{a}$ & 5.2703 & 9.1816 & 15.3097 & 91.192 & 167.532 & 88.934 & 159.9049 & 1.870 \\
\hline DFT $(P=0.4310 \mathrm{GPa})^{b}$ & 5.2868 & 9.3761 & 15.3193 & 88.522 & 168.097 & 91.314 & 156.5687 & 1.910 \\
\hline
\end{tabular}

${ }^{a} \mathrm{P}=(1.183,-0.003,-0.383) \mathrm{GPa} ;{ }^{b} \mathrm{P}=(1.887,0.016,-0.610)$
A. [100]
B. [010]
C. [001]
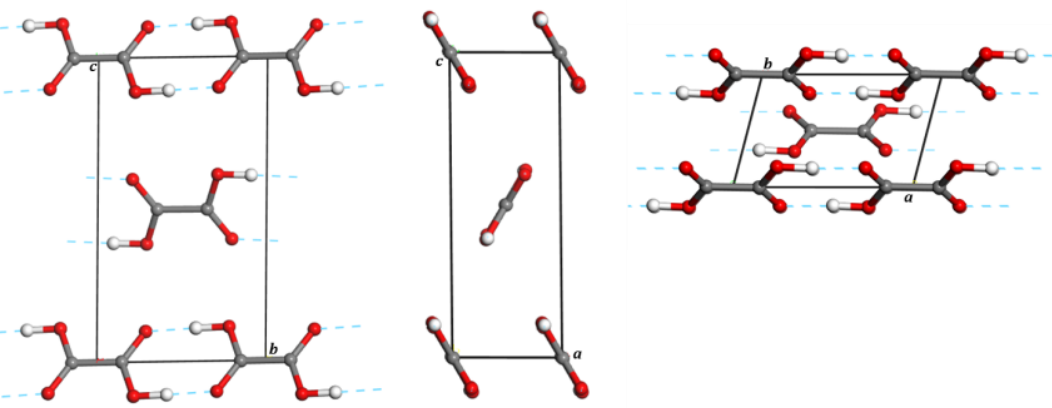

Figure 13. Calculated triclinic crystal structure of $\beta$-oxalic acid at $\mathrm{P}=0.2657 \mathrm{GPa}$. Color code: Grey-C; Red-O; White-H. 


\section{PCCP}

\section{Conclusions}

The structural and mechanical properties of oxalic acid dihydrate and the $\alpha$ and $\beta$ polymorphic forms of anhydrous oxalic acid were determined using theoretical solid-state methods. The calculated structural properties were found to be in very good agreement with the corresponding experimental data. The differences in the calculated cell volumes and densities with respect to the experimental values were about $2.7 \%, 0.9 \%$ and $1.2 \%$, respectively. The value of the difference for oxalic acid dihydrate was obtained from the comparison with the experimental results at the temperature of $100 \mathrm{~K}$. The comparison with the results at $300 \mathrm{~K}$ was considerably improved due to the large dependence of the crystal structure parameters on the temperature. Additional improvement may be expected from the comparison with experimental data at even lower temperatures. The X-ray powder diffraction patterns of these materials calculated from the optimized crystal structures were in excellent agreement with the experimental patterns.

The analysis of the computed stiffness tensors of these materials showed that their crystal structures are mechanically stable since they satisfy the Born mechanical stability conditions. A large number of relevant mechanical properties of these materials were reported. Among them, the bulk modulus and their pressure derivatives, the shear and Young moduli, the Poisson ratio, ductility and hardness indices and mechanical anisotropy measures were determined. Since these properties have not been measured experimentally, their values were predicted. Oxalic acid dihydrate and the $\alpha$ and $\beta$ forms of anhydrous oxalic acid are highly anisotropic ductile materials characterized by low hardness and bulk moduli. Their mechanical anisotropy is a direct consequence of their crystal structures since the chemical bonding between the atoms comprising the corresponding unit cells is very distinct for the different directions.

The three materials exhibit negative Poisson ratios as shown from the analysis of the surfaces of minimum Poisson ratio. The computed values of the minimum Poisson ratio were -0.24 , -0.45 and -0.60 , for oxalic acid dihydrate and the $\alpha$ and $\beta$ polymorphic forms of anhydrous oxalic acid, respectively. The structures of these materials were optimized under the effect of external pressures applied in the direction of minimum Poisson ratio. The study of these structures revealed that the three materials display also the phenomenon of negative linear compressibility for applied pressures larger than about 0.25 , 1.37 and $0.10 \mathrm{GPa}$, respectively. Oxalic acid dihydrate undergoes a pressure induced phase transition for negative applied pressures smaller than about $-0.045 \mathrm{GPa}$. The $\alpha$ and $\beta$ polymorphic forms of anhydrous oxalic acid also undergo pressure induced phase transitions for positive pressures larger than $\sim 1.91$ and $\sim 0.21 \mathrm{GPa}$, respectively.

Oxalic acid dihydrate and anhydrous oxalic acid are molecular crystals whose structures contain chains and sheets which are held together by weak van der Waals forces only. This weak interaction accommodates the variations of the crystal structures caused by the applied pressures, but the resulting deformations are counterintuitive and lead to the anomalous mechanical behavior of these materials.

From this work, it may be concluded that many other simple organic materials are likely to display an anomalous mechanical behavior. Due to the wide range of structures present in natural organic minerals and the great versatility of organic synthesis, this feature points to the need of performing systematic studies of the mechanical properties of organic materials. Such studies could reveal the existence of a large number of NPR and NLC organic materials with structures closely related to those of the oxocarbon and oxalic acids. This conclusion is important because the materials displaying these anomalous mechanical properties have a very wide range of useful applications and these properties have rarely been studied for organic materials.

\section{Conflicts of interest}

There are no conflicts to declare.

\section{Note added in revision}

Recently, large negative linear compressibilities have been found in metal-organic materials containing zinc, cadmium, and iron. The results will be reported in a forthcoming paper: $F$. Colmenero and V. Timon, to be submitted.

\section{Acknowledgements}

Supercomputer time by the CTI-CSIC center is greatly acknowledged. I want to thank Dr. Ana María Fernández for reading the manuscript and many helpful comments. I also would like to warmly thank J. Cobos, R. Escribano, V. Timón, C. Valdemoro, M. Yañez, J. F. Rico, A. M. Fernández and S. Raposo for their help, teaching, friendship, and support across the years. 


\section{References}

1 Encyclopaedia Britannica (eds.), Oxalic acid, http://www.britannica.com/science/oxalic-acid, accessed 1, November 2018.

2 H. Boerhaave, Elementa Chemiae, Johann Rudolph Imhoff, Basil, Switzerland, 1745.

3 F. P. Savary, Dissertatio Inauguralis De Sale Essentiali Acetosellæ, Jean François Le Roux, 1773.

4 L. Gmelin and H. Watts, Handbook of Chemistry, Cavendish Society, London, 1855.

5 T. Bergman and J. Afzelius, Dissertatio chemica de acido sacchari, Erdman, Uppsala, Sweden, 1776.

6 C. W. Scheele, New Proc. Roy. Acad. Sci., 1784, 5, 183.

7 F. Wöhler, Proc. Roy. Acad. Sci., 1824, 328.

8 W. Riemenschneider and M. Tanifuji, Oxalic acid. In Ullmann's Encyclopedia of Industrial Chemistry, Wiley-VCH, Weinheim, 2002.

9 E. Yonemitsu, T. Isshiki, T. Suzuki and Y. Yashima, U.S. Patent 3678107A, 1969.

10 H. T. Clarke and A. W. Davis, Org. Synth., 1921, 1, 67.

11 D. Vojta, M. Vrankic, M. Bertmer, G. E. Schaumann, Thermochim. Acta, 2016, 643, 73.

12 E. Bouwman, R. Angamuthu, P. Byers, M. Lutz and A. L. Spek, Science, 2010, 327, 313.

13 N. Casati, In: High Pressure Crystallography: From Fundamental Phenomena to Technological Applications, E. Boldyreva and P. Dera (eds.), Springer, Berlin, 2010.

14 P. Macchi, N. Casati, W. G. Marshall and A. Sironi, CrystEngComm., 2010, 12, 2596.

15 N. Casati, P. Macchi and A. Sironi, Chem. Commun., 2009, 0, 2679.

16 N. Casati, A. Jephcoat, H. Wilhelm and P. Macchi, Acto Crystallogr. A, 2014, 70, C898.

17 A. K. Mishra, C. Murli, H. Bhatt and S. M. Sharma, AIP Conf Proc., 2014, 1591, 136

18 H. Bhatt, A. K. Mishra, C. Murli, A. K. Verma, N. Garg, M. N. Deo and S. M. Sharma, Phys. Chem. Chem. Phys., 2016, 18 8065.

19 H. Bhatt, C. Murli, A. K. Mishra, A. K. Verma, N. Garg, M.N. Deo, R. Chitra and S. M. Sharma, J. Phys. Chem. B., 2016, 120,851

20 S. K. Sikka and S. M. Sharma, Phase Trans., 2008, 81, 907.

21 F. M. McCubbin, D.A. Sverjensky, A. Steele and B. Mysen, Am. Mineral., 2014, 99, 2258.

22 M. D S. Kumar, M. Akaishi and S. Yamaoka, J. Crystal Growth, 2000, 213, 203.

23 A. Ponchitra, K. Balasubramanian and K. M. S. Meena, Int. J. Sci. Eng. Manage., 2017, 2, 160.

24 F. R. Ahmed and D. W. J. Cruickshank, Acta Crystallogr., 1953, 6, 385

25 F. F. Iwasaki, H. Iwasaki and Y. Saito, Acta Crystallogr., 1967, 23, 64 .

26 T. M. Sabine, G. W. Cox and B. M. Craven, Acta Crytallogr. B, 1969, 25, 2437.

27 R. G. Delaplane and J. A. Ibers, Acta Crytallogr. B, 1969, 25, 2423

28 P. Coppens, T. M. Sabine, R. G. Delaplane and J. A. Ibers, Acta Crytallogr. B, 1969, 25, 2451

29 P. Coppens and T. M. Sabine, Acta Crytallogr. B, 1969, 25 2442.

30 D. Michell, A. P. Smith and T. M. Sabine, Acta Crytallogr. B, 1969, 25, 2458.

31 P. Coppens, J. Dam, S. Harkema, D. Feil, R. Feld, M. S. Lehman, R. Goddard, et al., Acta Crystallogr. A, 1984, 40, 184.

32 Y. Wang, C. Tsai and W. L. Liu, Acta Crystallogr. B, 1985, 41, 131.
33 R. H, Feld, Ph. D. Thesis, Phillips Universität, Marburg/Lahn, Germany, 1980.

34 A. Martin and A. A. Pinkerton, Acta Crystallogr. B, 1998, 54, 471.

35 A. Lehmann, P. Luger, C. W. Lehmann and R. M. Ibberson, Acta Crystallogr. B, 1994, 50, 344.

36 D. Zobel, P. Luger, W. Dreissig and T. Koritsanszky, Acta Crytallogr. B, 1992, 48, 837.

37 J. L. Derisen and P. H. Smit, Acta Crystallogr. B, 1974, 30 2240.

38 D.J. Grimwood and D. Jayatilaka, Acta Crystallogr. A, 2001, 57,87

39 D. Jayatilaka and D. J. Grimwood, Acta Crystallogr. A, 2001, 57, 76.

40 J. Stare and D. Hadzi, J. Chem. Theor. Comput., 2014, 10 1817.

41 R. G. Griffin, A. Pines, S. Pausak and J. S. Waugh, J. Chem. Phys., 1975, 63, 1267.

42 E. Ebisuzaki and S. M. Angel, J. Raman Spectrosc., 1981, 11, 306.

43 H. G. M. de Wit, J. A. Bouwstra, J. G. Blok and C. G. de Kruif, J. Chem. Phys., 1983, 78, 1470.

44 M. Khavani, M. Izadyar and A. Jamsaz, Progr. React. Kin. Mech., 2017, 42, 44

45 S. Hussain, G. A. Khan and M. Shabeer, Asian J. Research Chem., 2012, 5, 1323.

46 A. Apelblat, J. Chem. Thermodyn., 1986, 18, 351.

47 A. Apelblat and E. Manzurola, J. Chem. Thermodyn., 1987 19, 317.

48 C. Dobrogowska, L. G. Hepler and A. Apelblat, J. Chem Thermodyn., 1990, 22, 167.

49 M. Remko, K. R. Liedl and B.M. Rode, J. Chem. Soc. Perkin Trans., 1996, 2, 1743.

50 L. Gontrani, M. Bonomo, N. V. Plechkova, D. Dini and R. Caminiti, Phys. Chem. Chem. Phys., 2018, 20, 30120.

51 R. S. Lakes, Annu. Rev. Mater. Res., 2017, 47, 63.

52 G. N. Greaves, A. L. Greer and R. S. Lakes, Nature Mater., 2011, 10, 823.

53 R.S. Lakes, Science, 1987, 235, 1038

54 R. H. Baughman, S. Stafström, S. Cui and S. O. Dantas, Science, 1998, 279, 1522.

55 J. A. Kornblatt, E. B. Sirota, H. E. King, R. H. Baughman and C. Cui, Science, 1988, 281, 143.

56 A. B. Cairns and A. L. Goodwin, Phys. Chem. Chem. Phys., 2005, 17, 20449

57 D. A. Rychkov, J. Stare and E. V. Boldyreva, Phys. Chem. Chem. Phys., 2017,19, 6671.

58 E. V. Boldyreva, Phase Trans., 2009, 82, 303.

59 E. V. Boldyreva, Z. Kristallogr., 2014, 229, 236.

60 F. Colmenero, Mater. Res. Express., 2018, accepted for publication.

61 F. Colmenero, J. Cobos and V. Timon, J. Phys.: Cond. Matter. 2018. Under review.

62 F. Colmenero, Appl. Sci., 2018, 8, 2281.

63 S. I. Ranganathan and M. Ostoja-Starzewski, Phys. Rev. Lett., 2008, 101, 055504

64 Z. A. D. Lethbridge, R. I. Walton, A. S. H. Marmier, C. W Smith and K. E. Evans, Acta Mater., 2010, 58, 6444.

65 A. S. H. Marmier, Z. A. D. Lethbridge, R. I. Walton, C. W. Smith, S. C. Parker and K. E. Evans, Comput. Phys. Commun. 2010, 181, 2102.

66 A. F. Wells, Structural Inorganic Chemistry, Clarendon Press, Oxford, 1984

67 T. Chiba, G. Soda, Bull. Chem. Soc. Jpn., 1971, 44, 1703

68 S. Camus, K. D. M. Harris, R. L. Johnston, Chem. Phys. Lett., 1997, 76, 186.

69 R. Chitra, A. Das, R. R. Choudhury, M Ramanadham and R. Chidambaram, Pramana, 2004, 63, 263. 
70 C. Samaniego, J. G. Rodríguez-Zavala, F. J. Tenorio, R. FloresMoreno, Mol. Cryst. Liq. Cryst., 2013, 575, 188.

71 K. A. Kovacs, P. Grof, L. Burai, M. Riedel, J. Phys. Chem. A., 2004, 108,11026.

72 Ullmann's Encyclopedia of Industrial Chemistry, Wiley-VCH, Weinheim, 2002.

73 F. Abraham, B. Arab-Chapelet, M. Rivenet, C. Tamain and S. Grandjean, Coord. Chem. Rev., 2014, 266-267, 28.

74 L. Han, S. Xie, J. Sun and Y. Jia, IOP Conf. Ser.: Mater. Sci. Eng., 2017, 182, 012010.

75 L. Han, S. Xie, S. Liu, J. Sun, Y. Jia and Y. Jing, Appl. Energy, 2017, 185, 762.

76 L. P. Zill, Arch. Biochem. Byophys., 1955, 69, 473.

77 A. Sanchez Miron, E. Molina Grima, J.M. Fernandez Sevilla, Y. Chisti and F. Garcia Cama, J. Appl. Phycol., 2000, 12, 385.

78 A. Bertron, H. Ranaivomanana, N. Jacquemet, B. Erable, C. Sablayrolles, G. Escadeillas and A. Albrecht, EPJ Web Conf., 2013, 56, 01002.

79 Oxalic acid. Immediately Dangerous to Life and Health Concentrations (IDLH), National Institute for Occupational Safety and Health (NIOSH), https://www.cdc.gov/niosh/idlh /144627.html, accessed 1, November 2018.

80 E. H. Vernot, J. D. MacEwen, C. C. Haun and F. R. Kinkead, Toxicol. Appl. Pharmacol., 1977, 42, 417.

81 D. C. Haytowitz and R. H. Matthews, Agriculture Handbook No. 8-11: Composition of Foods: Vegetables and Vegetable Products, US Department of Agriculture (USDA) Washington DC, 1984; Oxalic Acid Content of Selected Vegetables: https://www.ars.usda.gov/northeast-area/ beltsville-md-bhnrc/beltsville-human-nutrition-researchcenter/nutrient-data-laboratory/docs/oxalic-acid-contentof-selected-vegetables/, accessed, 1, November 2018

82 M. V. Dutton and C. S. Evans, Can. J. Microbiol., 1996, 42, 881.

83 J. A. Wesson and M. D. Ward, Elements, 2007, 3, 415.

84 R. Selvaraju, A. Raja and G. Thiruppathi, Spectrochim. Acta A, 2012, 99, 205.

85 J. P. Pestaner, F. G. Mullick and F. B. Johnson, Arch. Pathol. Lab. Medicin., 1996, 120, 537.

86 W. Novoa, A. Winer, A. Glaid and G. Schwert, J. Biol. Chem. 1958, 234, 1143.

87 A. Le, C. Cooper, A. Gouw, R. Dinavahi, A. Maitra, L. Deck, R. Royer, D. Vander, G. Semenza and C. Dang, Proc. Natl. Acad. Sci. U.S.A., 2010, 107, 2037.

88 B. Salvadori, V. Errico, M. Mauro and L. Dei, Spectrosc. Lett., 2003, 36, 501.

89 I. Lamprecht, A. Reller, R. Riesen and H. G. Wiedemann, J. Thermal Anal., 1997, 49, 1601.

90 M. Del Monte and C. Sabbioni, Environ. Sci. Technol., 1983, 17, 518.

91 H. G. M. Edwards, K. A. E. Edwards, D. W. Farwell, I. R. Lewis and M. R. D. Seaward, J. Raman Spectrosc., 1994, 25, 99.

92 J. Girbal, J. L. Prada, R. Rocabayera and M. Argemi, Radiocarbon, 2001, 43, 637.

93 L. Maiore, M. C. Aragoni, G. Carcangiu, O. Cocco, F. Isaia, V. P. Meloni, A. Murru, E. Tuveri and M. Arca, J. Colloid Interface Sci., 2015, 448, 320.

94 C. Sabbioni and G. Zappia, Aerobiologia, 1991, 7, 31.

95 P. Saxena and L. M. Hildeman, J. Atmos. Chem., 1996, 24, 57.

96 J. Chen, S, Jiang, Y. R. Liu, T. Huang, C. Y. Wang, S. K. Miao, Z. Q. Wang, Y. Zhan and W. Huang, RSC Adv., 2017, 7, 6374

97 M. C. Payne, M. P. Teter, D. C. Ailan, T. A. Arias, J. D. Joannopoulos, Rev. Mod. Phys., 1992, 64, 1045

98 F. Colmenero, L. J. Bonales, J. Cobos, V. Timón, J. Phys. Chem. C, 2017, 121, 5994.

99 F. Colmenero, L. J. Bonales, J. Cobos, V. Timón, J. Solid. State Chem., 2017, 253, 249.
100 F. Colmenero, L. J. Bonales, V. Timón, J. Cobos, Clay Miner., 2018, 53, 377.

101 F. Colmenero, J. Cobos, V. Timón, Inorg. Chem., 2018, 57, 4470.

102 F. Colmenero, A. M. Fernández, J. Cobos, V. Timón, RSC Adv., 2018, 8, 24599.

103 F. Colmenero, Ph. D. Thesis, Universidad Autónoma de Madrid, Madrid, 2017; 443 pp.

104 F. Colmenero, In: Minerals, K. S. Essa (ed.), InTechOpen, London, 2018. ISBN: 978-953-51-6784-6.

105 P. F. Weck, E. Kim, E. C. Buck, RSC Adv., 2015, 5, 79090

106 P. F. Weck, E. Kim, J. Phys. Chem. C, 2016, 120, 16553.

107 N. R. Keskar, J. R. Chelikowsky, Nature, 1992, 358, 222.

108 J. N. Grima, R. Gatt, A. Alderson, K. E. Evans, Mater. Sci. Eng. A Struct., 2006, 423, 219.

109 J. N. Grima, R. Gatt, V. Zammit, J. J. Williams, K. E. Evans, A. Alderson, R. I. Walton, J. Appl. Phys., 2007, 101, 086102.

110 F. X. Coudert, Phys. Chem. Chem. Phys., 2016, 18, 9079.

111 F. X. Coudert, Chem. Mater., 2017, 29, 7833.

112 Y. T. Yao, K. L. Alderson, A. Alderson, Cellulose, 2016, 23, 3429.

113 J. C. Tan, B. Civalleri, A. Erba, E. Albanese, CrystEngComm., 2015, 17, 375.

114 M. R. Ryder, J. C. Tan, Dalton Trans., 2016, 45, 4154.

115 H. Sun, S. Mukherjee, C. V. Singh, Phys. Chem. Chem. Phys., 2016, 18, 26736.

116 Y. Du, J. Maassen, W. Wu, Z. Luo, X. Xu, P. D. Ye, Nano Lett., 2016, 16, 6701

117 W. Li, M. R. Probert, M. Kosa, M. T. D. Bennett, A Thirumurugan, R. P. Burwood, M. Parinello, J. A. Howard, A. K. Cheetham, J. Am. Chem. Soc., 2012, 134, 11940.

118 Y. Qiao, K. Wang, H. Yuan, K. Yang, B. Zou, J. Phys. Chem. Lett., 2015, 6, 2755.

119 C. S. Coates, J. W. Makepeace, A. G. Seel, M. Baise, B. Slater, A. L. Goodwin, Dalton Trans., 2018, 47, 7263.

120 A. Marmier, P. S. Ntoahae, P. E. Ngoepe, D. G. Pettifor, S. C. Parker, Phys. Rev. B, 2010, 81, 172102.

121 L. Kang, X. Jiang, S. Luo, P. Gong, W. Li, X. Wu, Y. Li, X. Li, C. Chen, Z. Lin, Sci. Rep., 2016, 5, 13432.

122 J. Dagdelen, J. Montoya, M. De Jong, K. Persson, Nature Commun., 2017, 8, 323.

123 D. T. Ho, S. D. Park, S. Y. Kwon, K. Park, S. Y. Kim, Nature Commun., 2014, 5, 3255.

124 D. Wu, S. Wang, S. Zhan, S. J. Yuan, B. Yang, H. Chen, Phys. Chem. Chem. Phys., 2018, 20, 18924.

125 F. Hao, X. Liao, M. Li, H. Xiao, X. Chen, J. Phys.: Cond. Matter, 2018, 30, 315302.

126 H. Wang, Q. Li, Y. Gao, F. Miao, X. Zhou, X. G. Wan, New J. Phys., 2016, 18, 073016.

127 H. Wang, Z. D. Zhang, R. Q. Wu, L. Z. Sun, Acta Mater., 2013, 61, 2919.

128 H. Wang, X. Li, P. Li, J. Yang, Nanoscale, 2017, 9, 850.

129 X. F. Wang, T. E. Jones, W. Li, Y. C. Zhou, Phys. Rev. B, 2012, 85, 134108

130 S. Yalameha, A. Vaez, Int. J. Mod. Phys. B, 2018, 32, 1850129.

131 H. Hsueh, C. C. Lee, C. W. Wang, Phys. Rev. B, 2000, 61, 3851.

132 W. Ren, J. Ye, W. Shi, Z. K. Tang, C. T. Chan, P. Sheng, New J. Phys., 2009, 11, 103014.

133 J. P. Perdew, K. Burke, M. Ernzerhof, Phys. Rev. Lett., 1996 , 77, 3865.

134 S. Grimme, J. Comput. Chem. 2006, 27, 1787.

135 S. J. Clark, M. D. Segall, C. J. Pickard, P. J. Hasnip, M. I. J. Probert, K. Refson, M. C. Payne, Z. Kristallogr., 2005, 220 567.

136 MaterialsStudio, http://3dsbiovia.com/products/collabora tive-science/biovia-materials-studio/, accessed Sept. 27, 2018.

137 N. Troullier, J. L. Martins, Phys. Rev. B, 1991, 43, 1993. 
138 B. G. Pfrommer, M. Cote, S. G. Louie, M. L. Cohen, J. Comput. Phys., 1997, 131, 233.

139 H. J. Monkhorst, J. D. Pack, Phys. Rev. B, 1976, 13, 5188.

140 R. T. Downs, K. L. Bartelmehs, G. V. Gibbs, M. B. Boisen, Am Mineral., 1993, 78, 1104.

141 F. Colmenero, In: Density Functional Theory, D. GlossmanMitnik (ed.), InTechOpen, London, 2018. ISBN: 978-953-517020-4.

142 R. Yu, J. Zhu, H. Q. Ye, Comput. Phys. Commun., 2010, 181, 671.

143 J. F. Nye, Physical Properties of Crystals, Clarendon, Oxford, 1976.

144 S. Baroni, S. de Gironcoli, A. Dal Corso, Rev. Mod. Phys., 2001, 73, 515.

145 F. Birch, Phys. Rev., 1947, 71, 809.

146 R. J. Angel, Rev. Mineral. Geochem., 2000, 41, 35. EOSFIT 5.2 software, http://www.ccp14.ac.uk/ccp/webmirrors/rossangel/rja/soft/.10.2138/rmg.2000.41.2

147 F. Colmenero, J. Phys. Chem. Solids., 2019, 125, 31.

148 F. Fischer, G. Scholz, L. Batzdorf, M. Wilke, F. Emmerling, CrystEngComm., 2015, 17, 824.

149 M. Born, Math. Proc. Camb. Phil. Soc., 1940, 36, 160.

150 F. Mouhat, F. X. Coudert, Phys. Rev. B, 2014, 90, 224104.

151 W. Voigt, Lehrbuch der Kristallphysik, Teubner, Leipzig, 1962.

152 A. Reuss, Z. Angew. Math. Mech., 1929, 9, 49.

153 R. Hill, Proc. Phys. Soc. Lond. A, 1952, 65, 349.

154 S. F. Pugh, Phil. Mag., 1954, 45, 823.

155 H. Niu, P. Wei, Y. Sun, C. X. Chen, C. Franchini, D. Li, Y. Li, Appl. Phys. Lett., 2011, 99, 031901.

156 Y. Bouhadda, S. Djella, M. Bououdina, N. Fenineche, Y. Boudouma, J. Alloys Compd., 2012, 534, 20.

157 P. Ravindran L. Fast, P. A. Korzhavyi, B. Johansson, J. Wills, O. Eriksson, J. Appl. Phys., 1998, 84, 4891. 